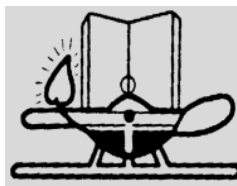

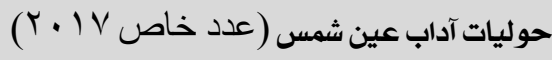

http://www.aafu.journals.ekb.eg

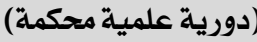

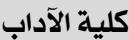

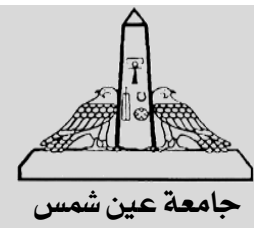

\title{
رعاية المالك و أثرها على تطور الخط
}

* إيمان مختار سعيد

معيدة بكلية الآداب جامعة عين شمس -قسم اللغات الثرقية وآدابها

يتناول هذا البحث الدور الكبير الذي لعبه ملوك و أمراء العصريين التيمورى و

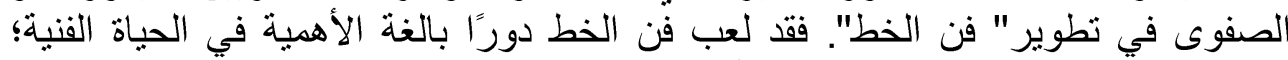

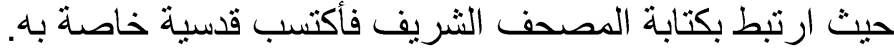
وقد قسمت الباحثة هذا البحث إلى مقدمة وقسمين، يتتاول القسم الأول العصر التيموري، و القسم الثاني العصر الصفوي؛ حيث تعرض الباحثة في كل قسم ازدهار الحياة التئن

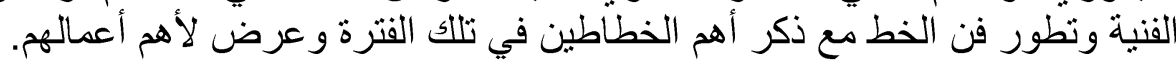

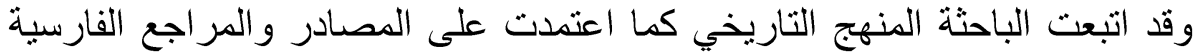

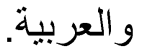


تعد فنون الكتاب الإسلامي من الفنون الإسلامية المهمة،حيث اشتملت هذه الفنون على فن التصوير وفن الخط وفن التذهيب. فيعد فن الخط من الفنون الهامة في التاريخ

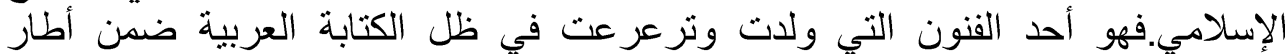
الحضارة الإسلامية.فقد دخل الخط مع ظهور الإسلام مرحلة من التطور السرئ السريع.

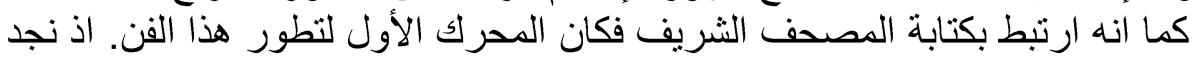

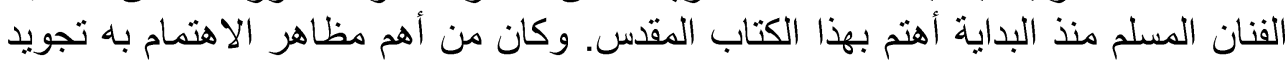
الخطوط التي يكتب بها هذا المصحف وابتكار الكثير من أنواع الخطوط الخداب.

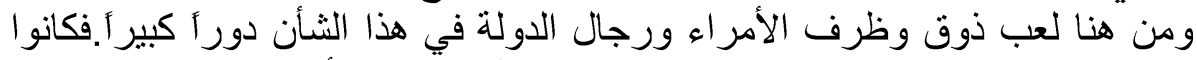

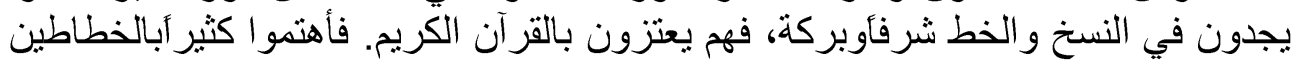

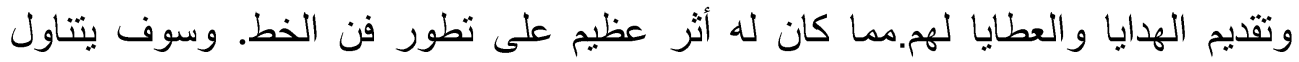

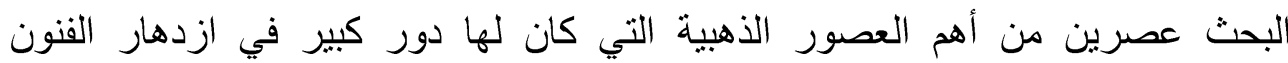
همالعصر التبيوري والعصن من الفمر الصفوي.

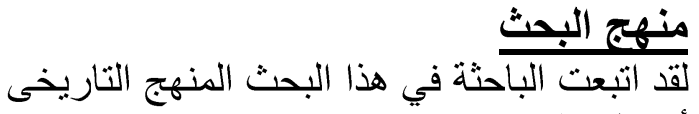
أهداف البحث: البع:

أتسليط الضوء البع: على الدور الكبير الذي لعبه ملوك و أمر اء العصريين التيموري والصفوي

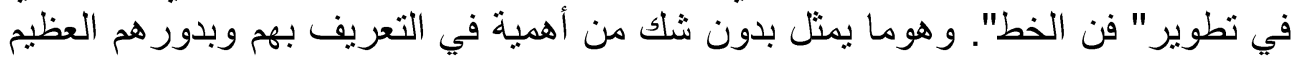
في ازدهار الحياة الفنية الإير انية.

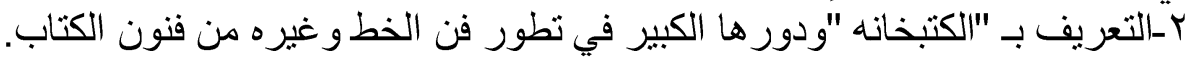

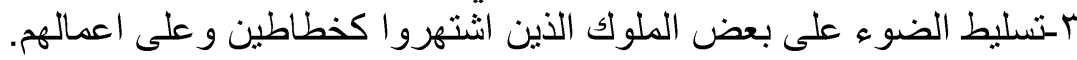

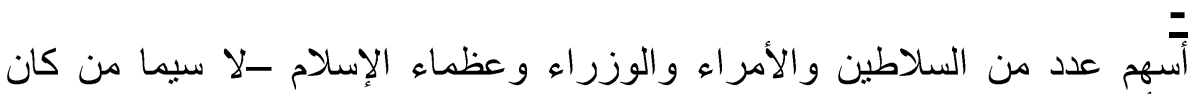
تمهيد:فارسي الأصل- في ترويج فن الخط ونشره و عد كثير آ منهم في زمرة واه الخطاطين.

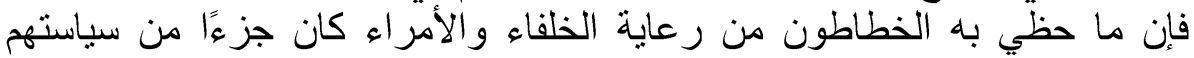

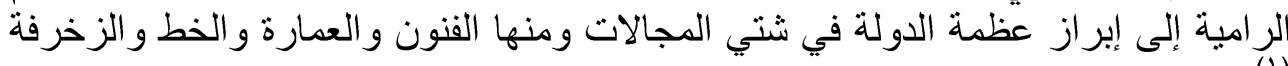
فالعناية بجودة الخط أمر طبيعي في الإسلام، كان الخطاطون أعظم الفنانين مكانة في

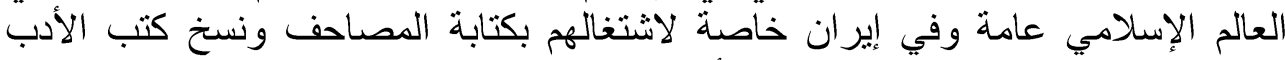

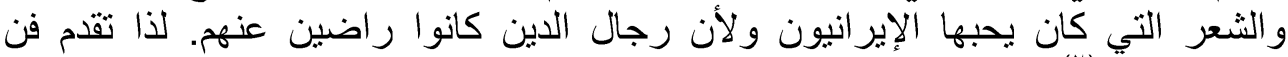
تحسين الخط (r). كما لعب ذوق وظرف الأمر اء ورجال الدولة في هذا الثأن دورآ كبيرآ، فقد كانوا

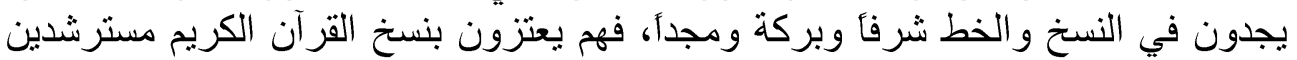

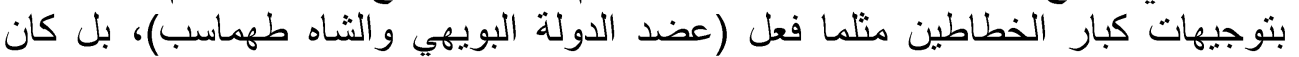

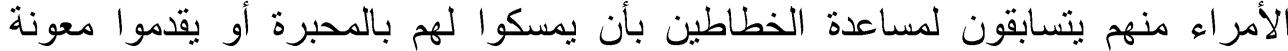

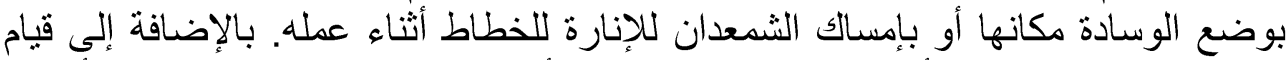

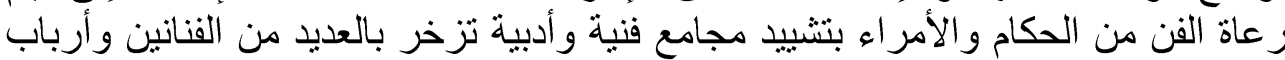

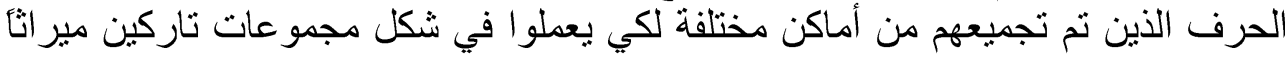


فنبا خالدأ من المخطوطات المصورة والأعمال المكتوبة و التي لا تز ال تزخر بها مكتبات

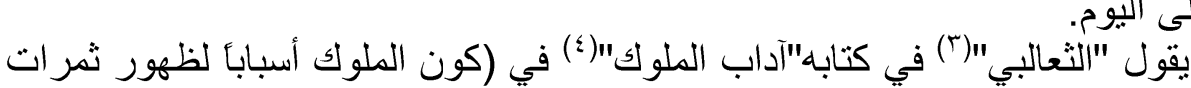

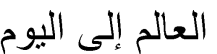
العلوم و الآداب ولطائف الصناعات):

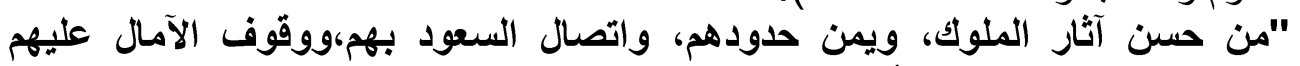

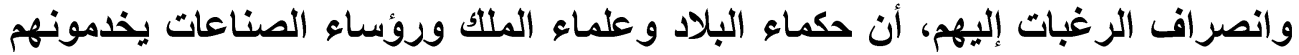

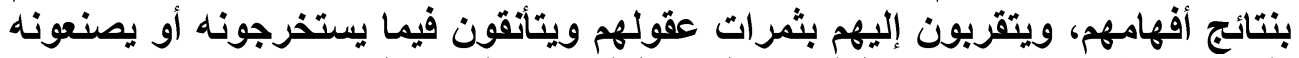

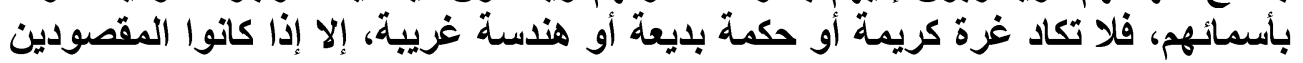

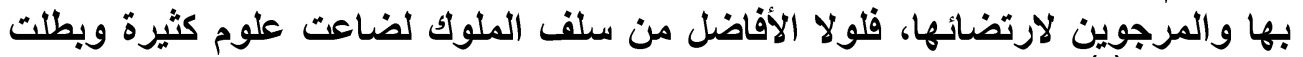

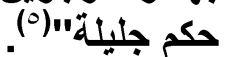

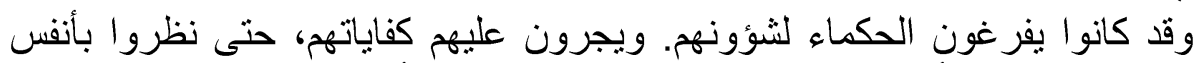

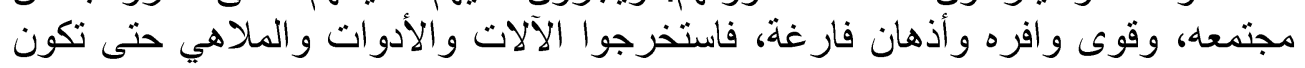

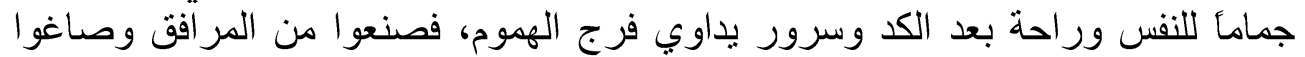

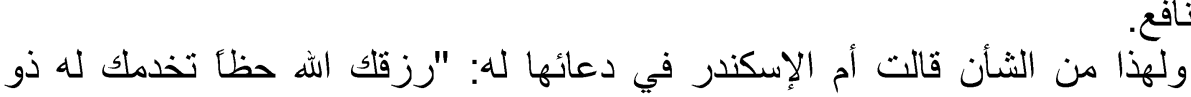

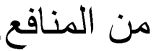

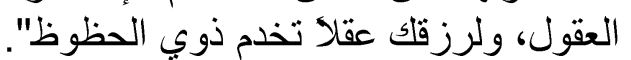

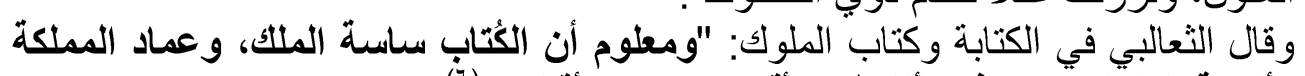

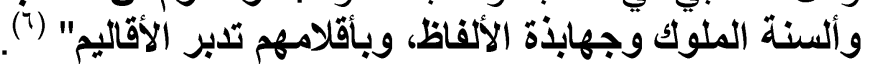

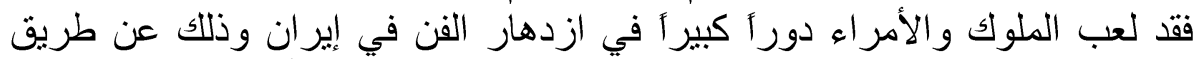

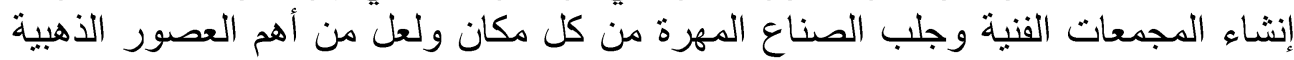

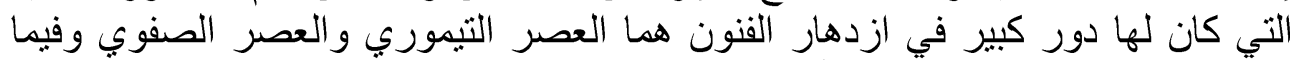
يلي عرض موجز لحقبتين من أهم فترات تاريخ إيران في الحضارة الإسلامية في هذا

العصر التيمورى: (

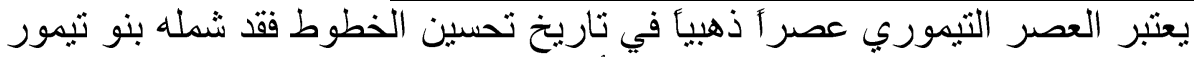

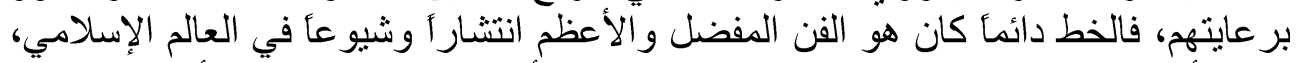

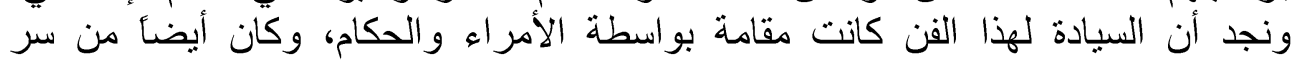

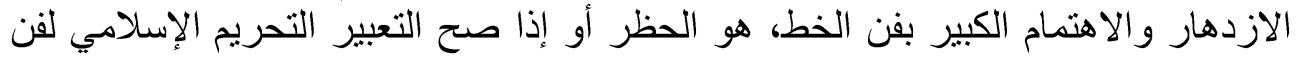

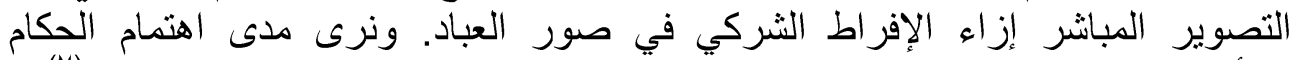

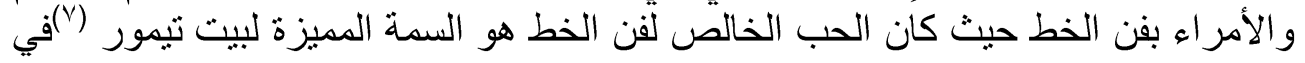

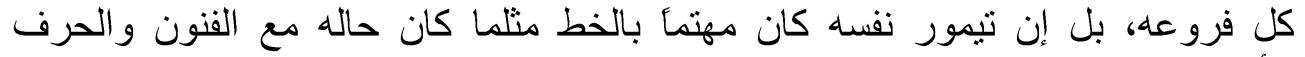

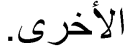

فيرجع السبب الأساسي في هذه النهضة الفنية التي ظهرت في العصر التيموري

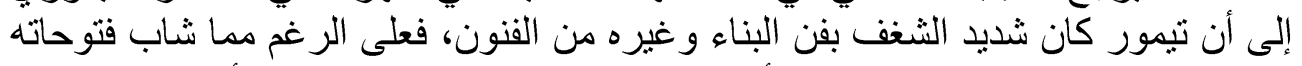

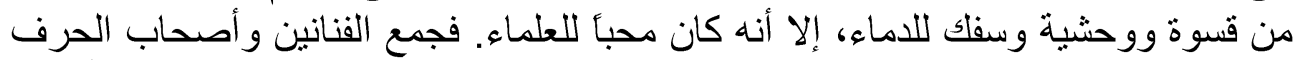

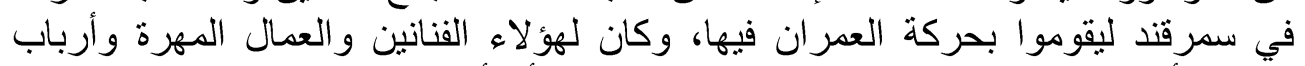

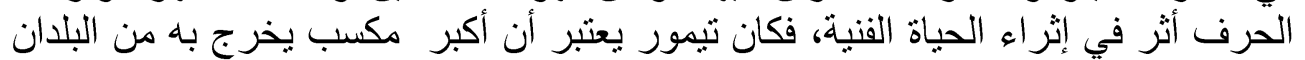

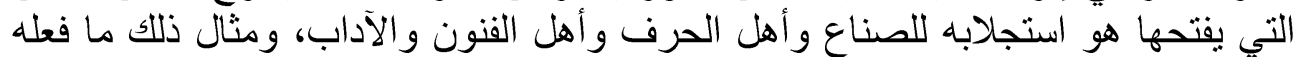

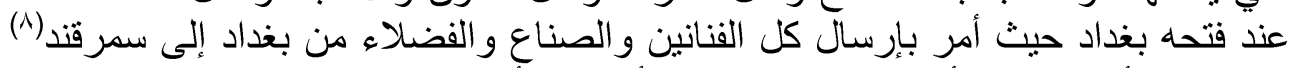

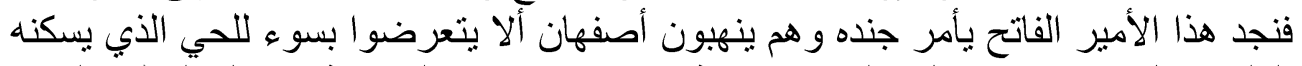

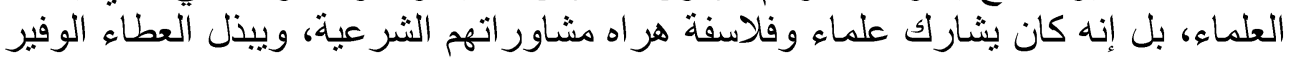




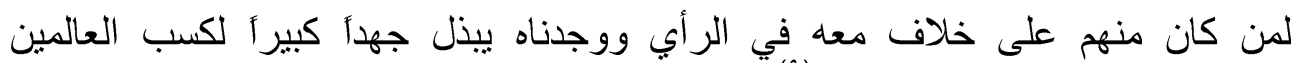

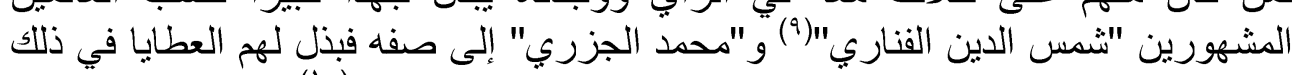

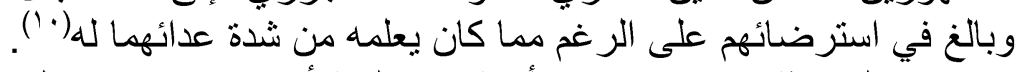

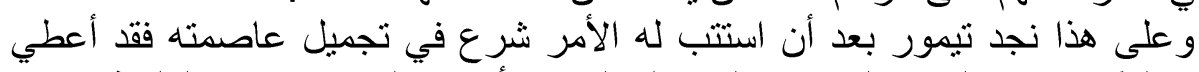

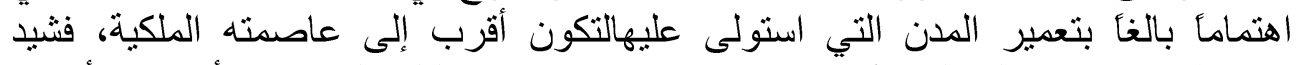

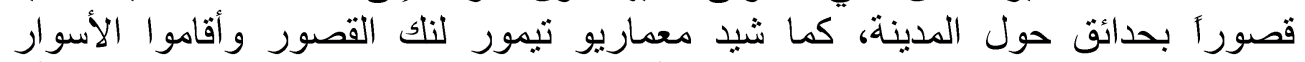

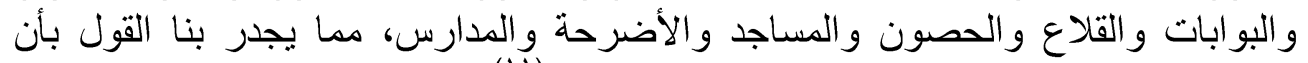

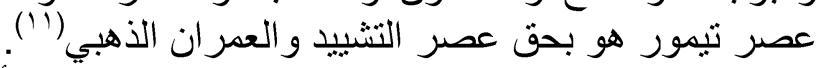

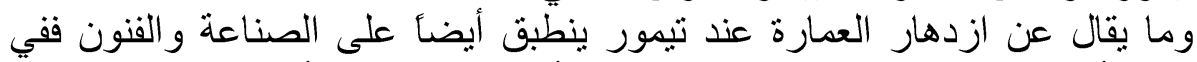

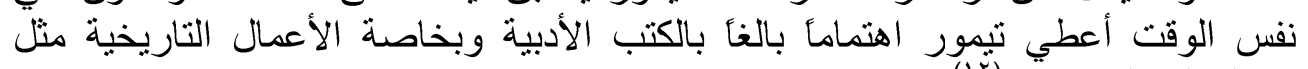

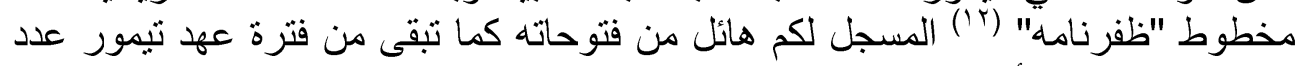

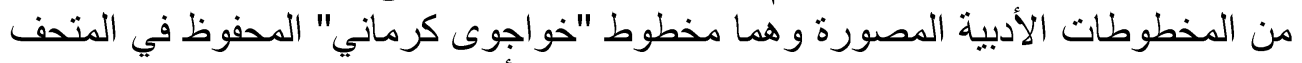

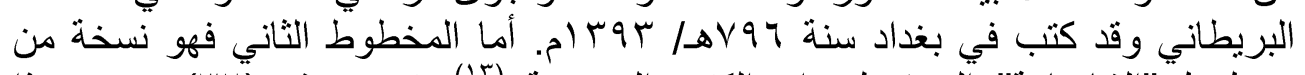

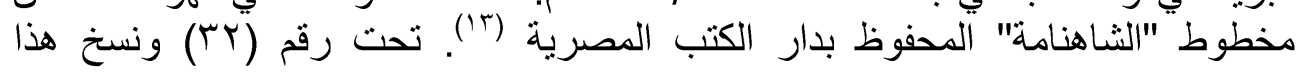

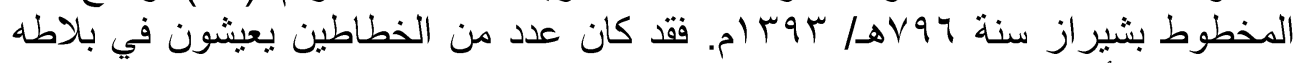

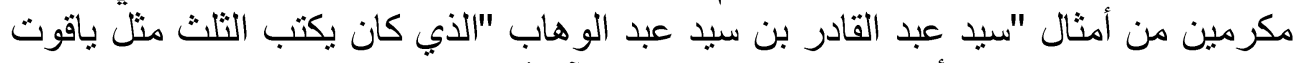

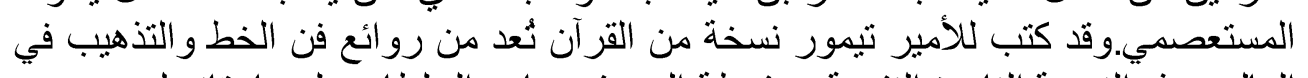

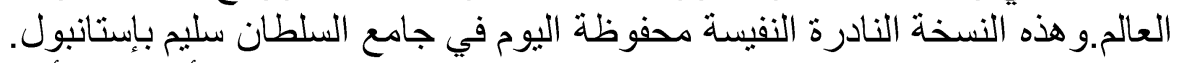

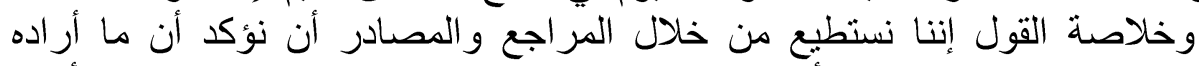

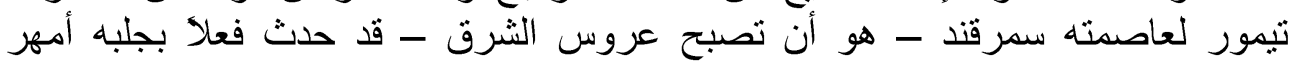

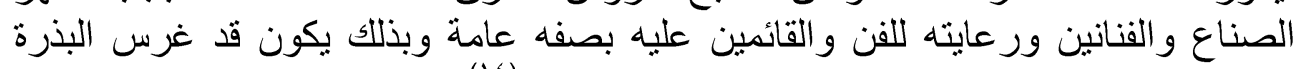

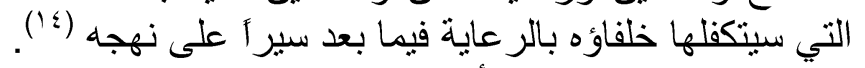

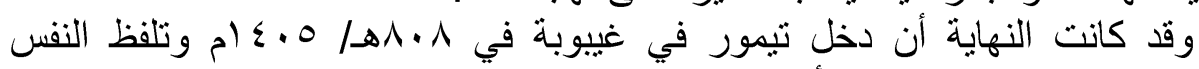

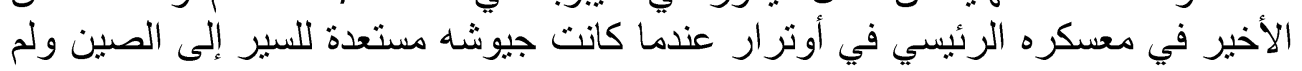

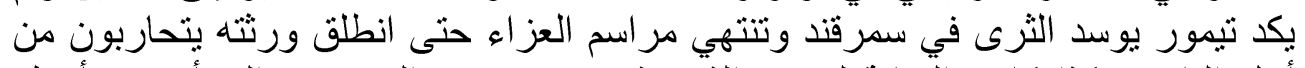

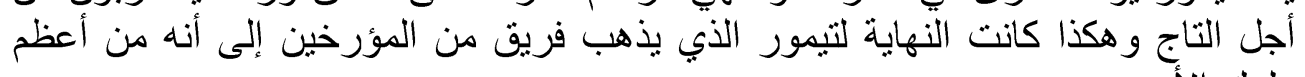

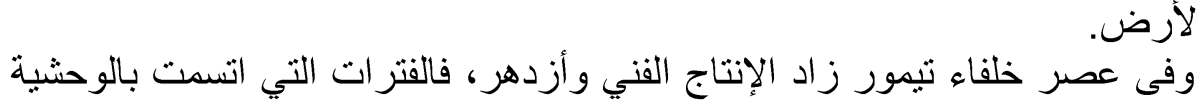

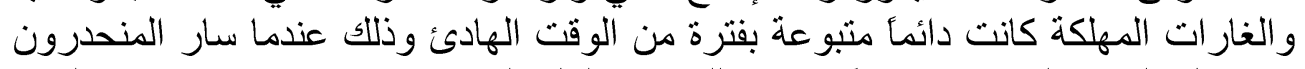

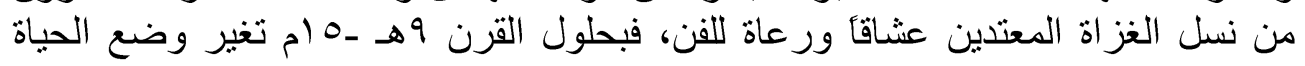

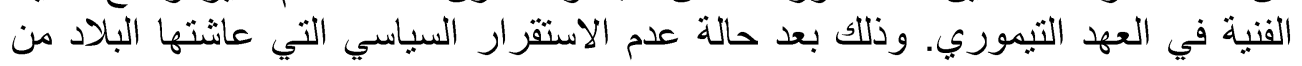

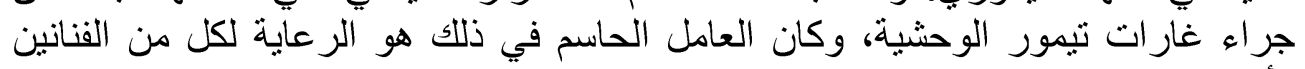

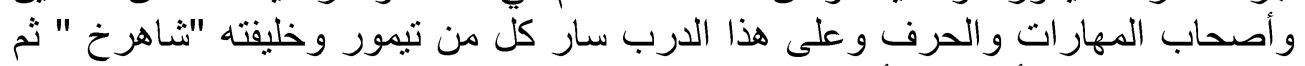

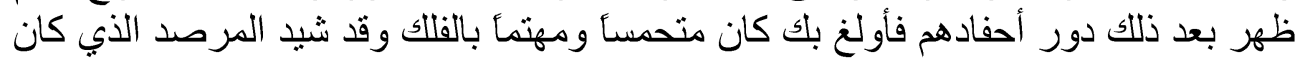

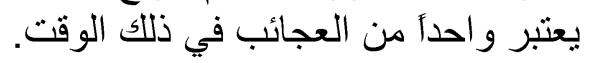

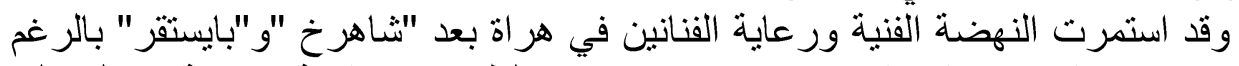

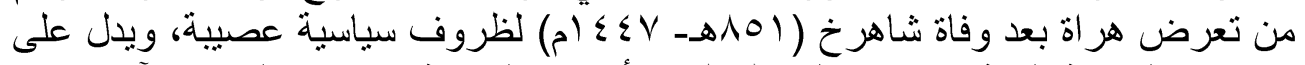

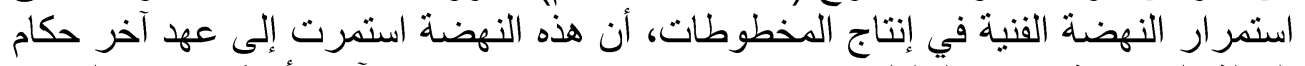

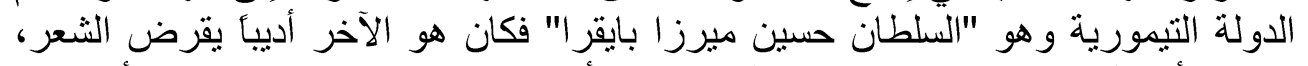

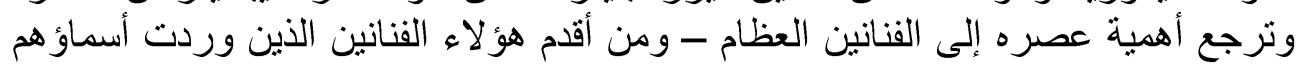


"روح الله ميرك الخر اساني" وترجع أهمية هذا المصور إلى أن بعض المصادر ذكرت أنه إنه كان استاذا لبهز اد أعظم المصوري" الفرين الإير انيين (10).

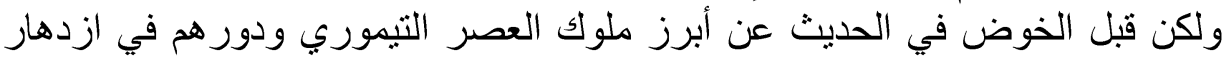

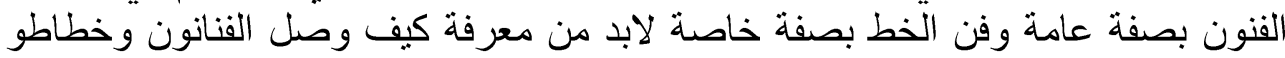

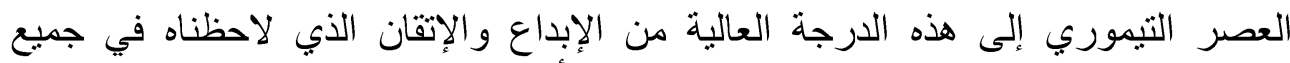
المخطوطات التيمورية؛ وتتركز الإجابة على هذه الأسئلة في ثناء الإن نقاط:

سبق أنب ذكرنا أن أصناغ تيمورلنك قد جلب العديد من الصناع و الفنانين المهرة من كل فن.

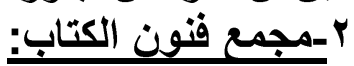
أما السبب الثاني فيكئبن في في مجمعات فنون الكتاب ورعاية السلاطين التيموريين

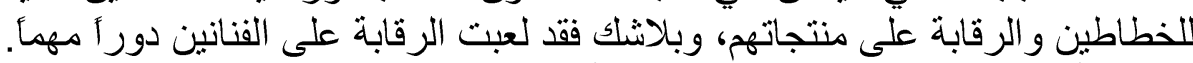

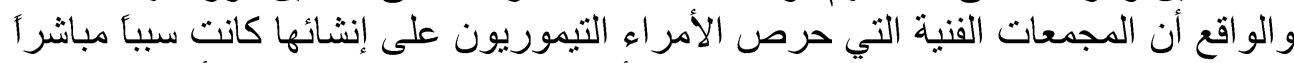

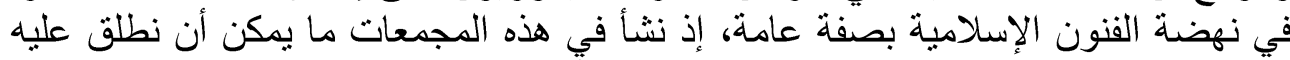

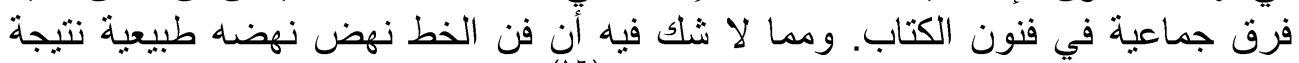

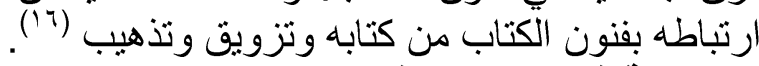

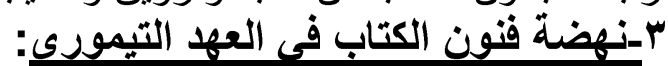

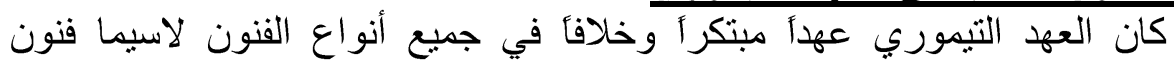

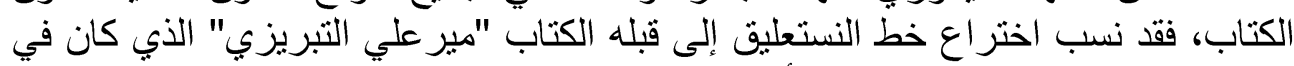

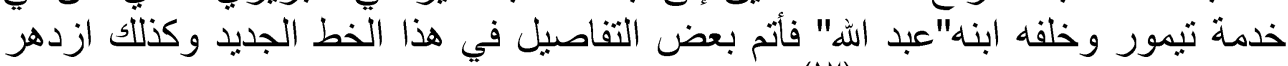

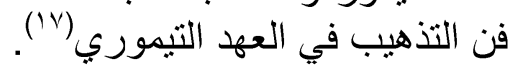

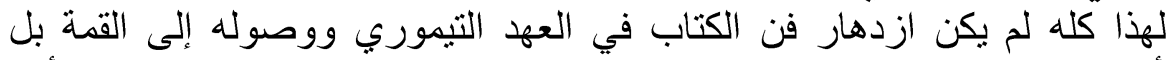

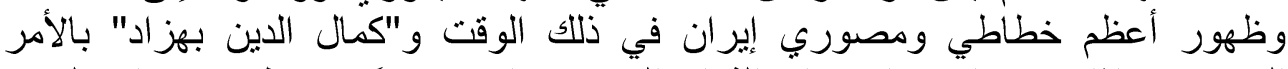

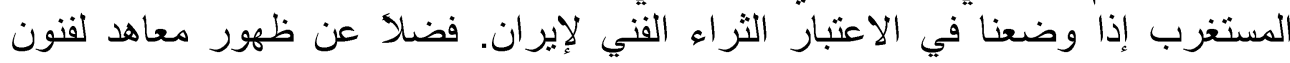

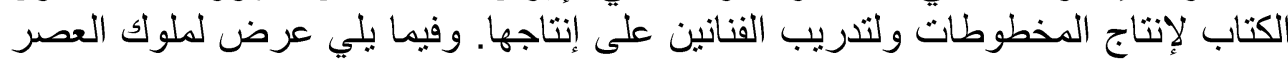

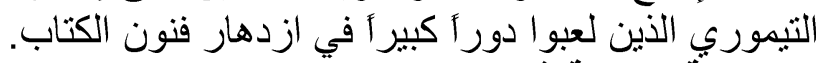

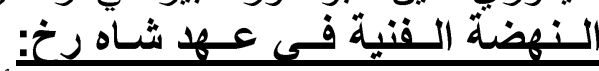

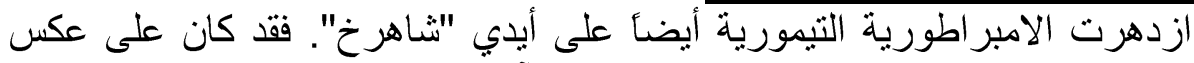

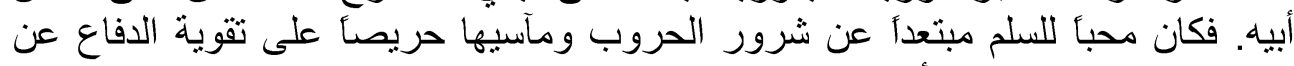

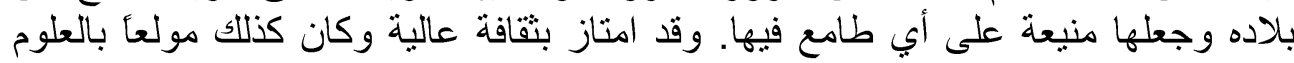

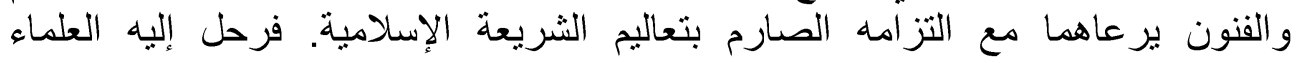

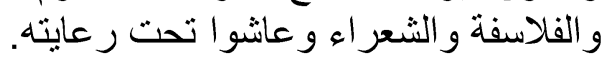

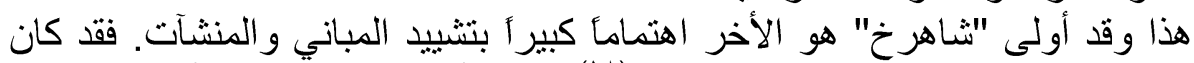

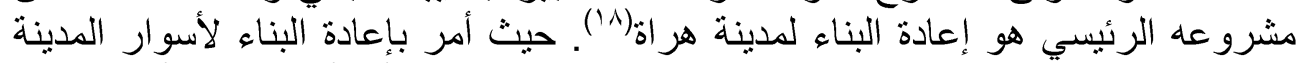

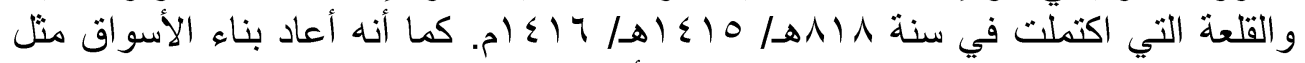

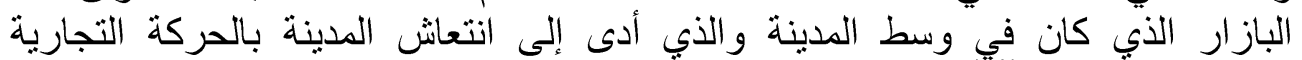

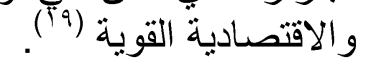

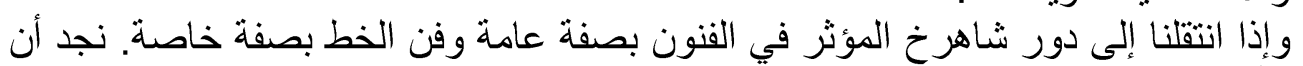

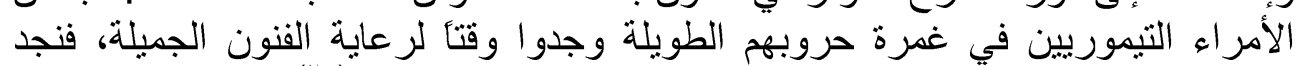

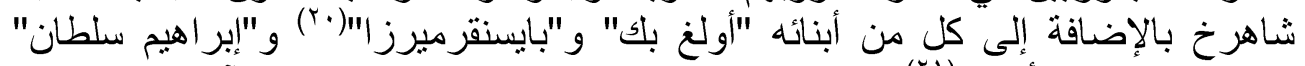

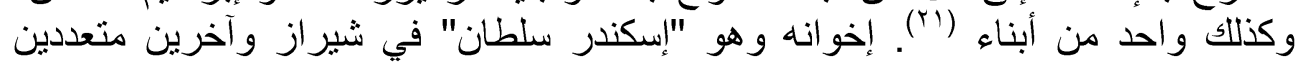


شجعو اكلا من المصورين و الخطاطين و الفنانين ليعملوا جيدأ داخل ورشة عمل منظمة أو

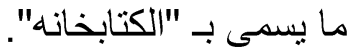

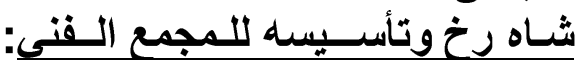

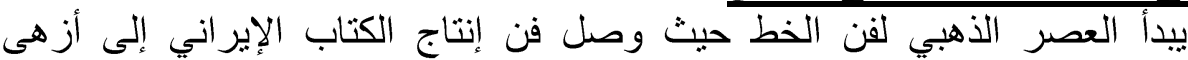

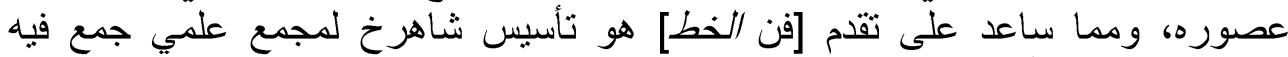

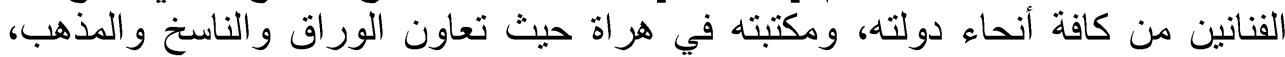

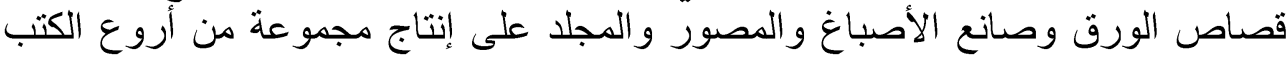

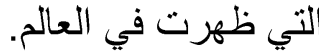

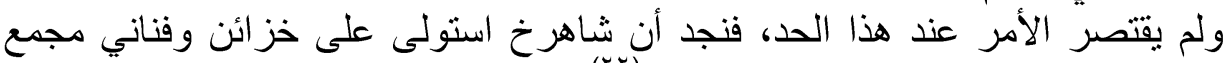

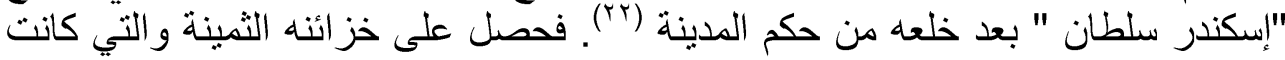
تضم بين نفائسها المخطوطات القيمة. وفى نفس الوقت نقل الخطاطين و الفنانين الذين عملوا لإسكندر إلى حاضرته الجديدة مدينة "هر اة".

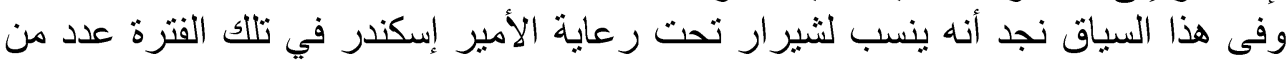
المخطوطات الهامة المنفذة بمجمعه منها: آنها:

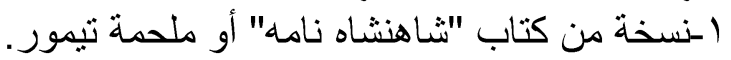

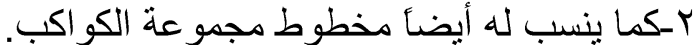

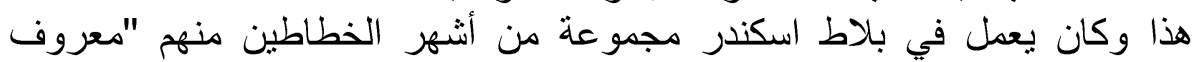
البغدادي " فكان من بين فناني مجمع إسكندر الفني وكان معروف هو هو الخطاط الرئيسي في

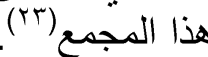

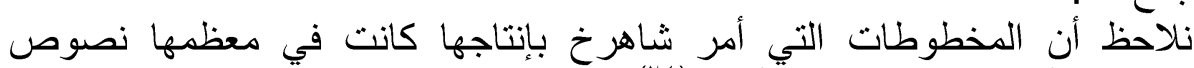

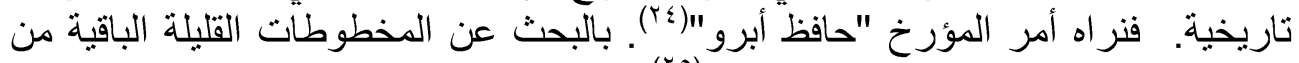

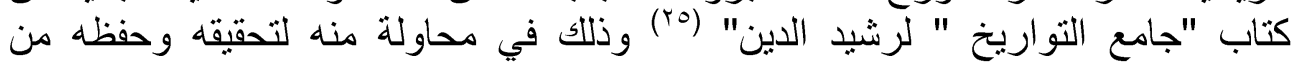

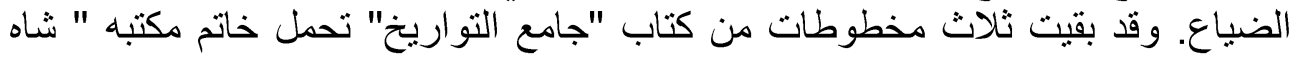

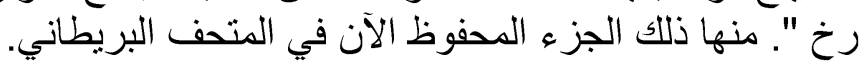

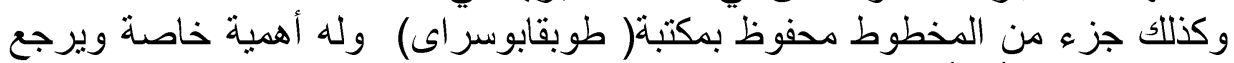
السبب في ذلك إلى أنه أضيفت إليه في عهد "شاهرخ خل منمنمات جديدة في مواضع لم لم تكن

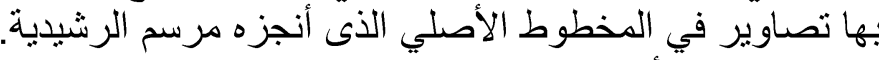

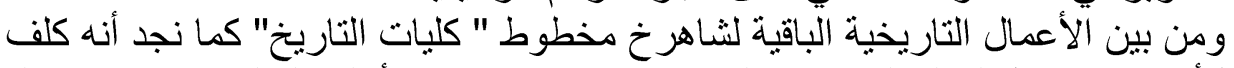

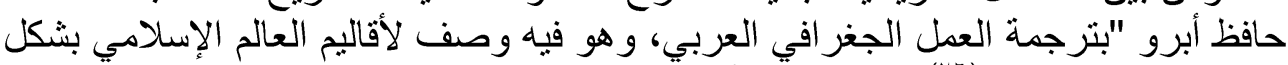

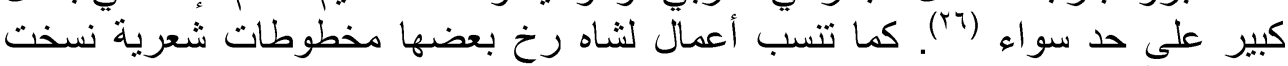

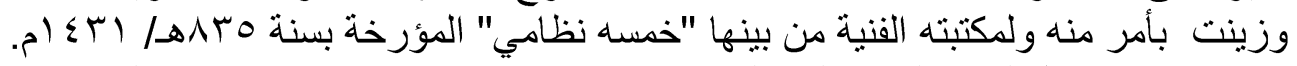

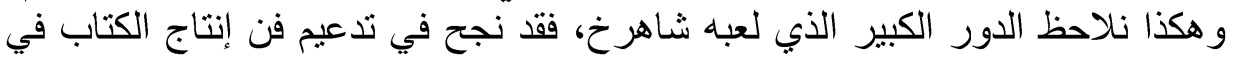

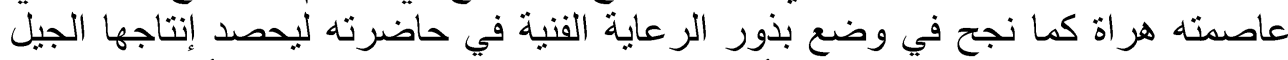

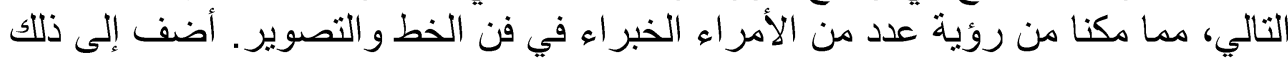
العدد الهائل من المخطوطات من رؤة المنفذة تحت الأدراء رعايتهم.

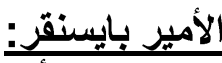

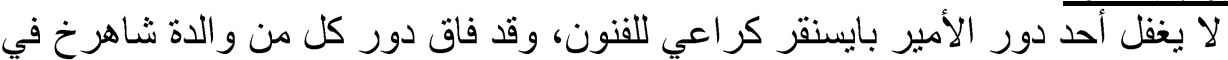

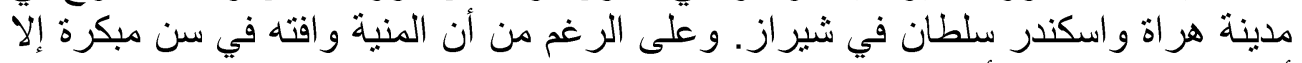

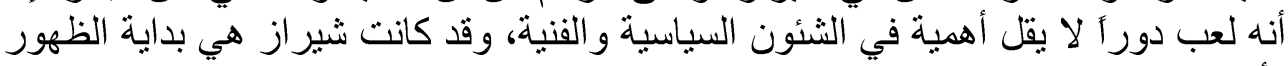

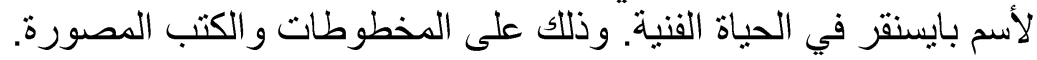




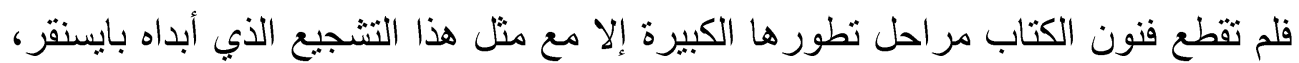

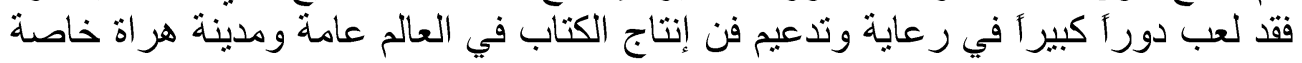

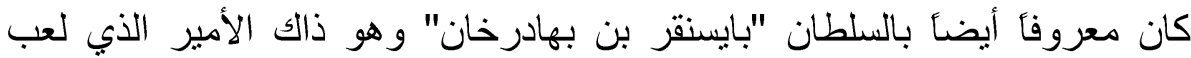

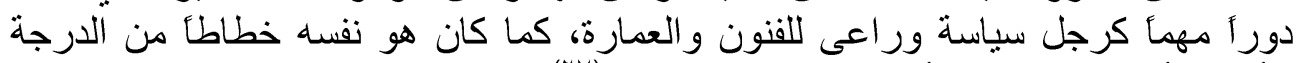

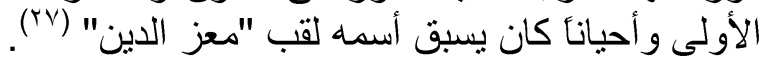

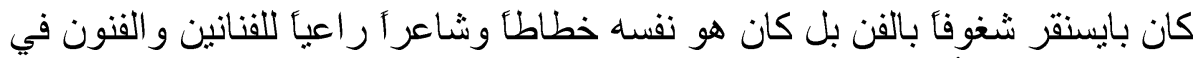

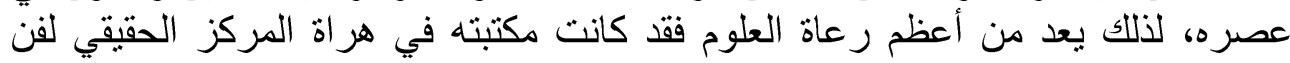

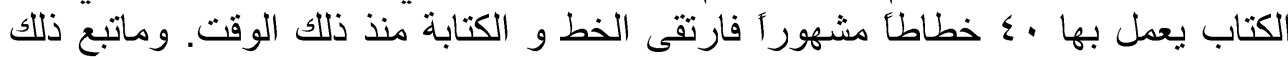

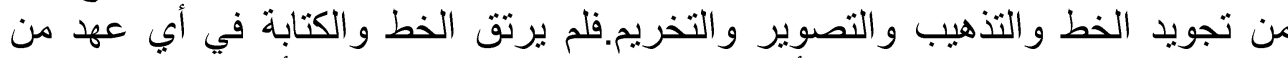

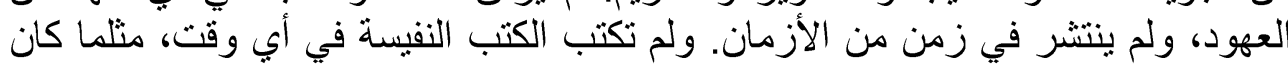
في هذا العصر.و لاتوجد من النسخ المكتوبة في عهده سوى نسخ قليلة جدأ في مكتبات إستانبول.

فقد أظهر منذ طفولته نزوعا لفن تزيين الكتب. تتلمذ بايسنقرميرزا في خطوط

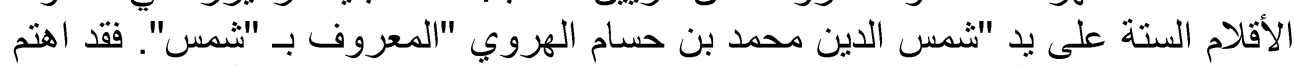

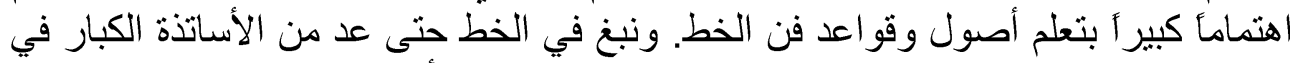

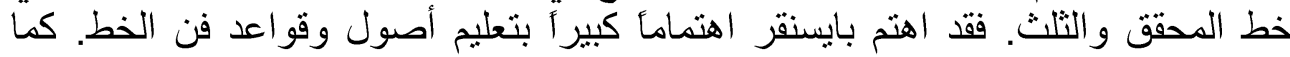
عنى بتزيين المخطوطات بالصور فبفضله انتقلت الزبنه عامة الفنية في التصوير وفير من شيراز

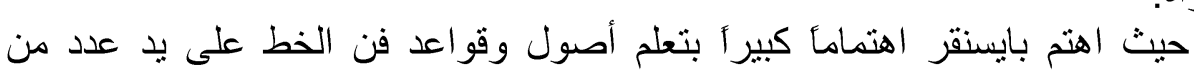
إلى هر اة.

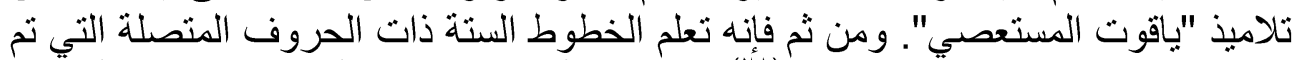

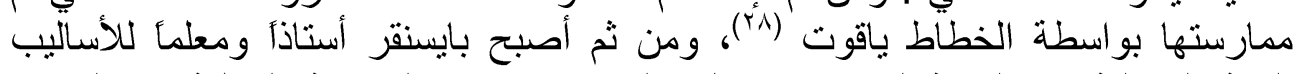

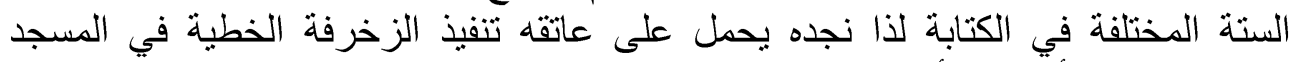

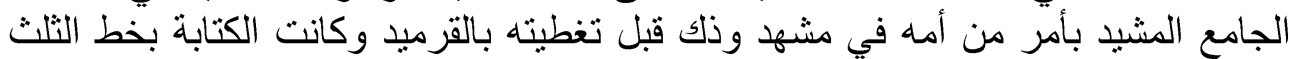

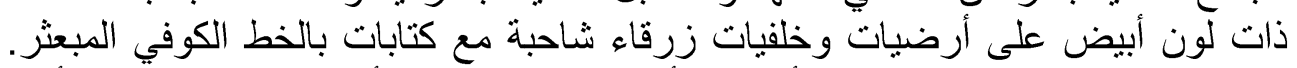

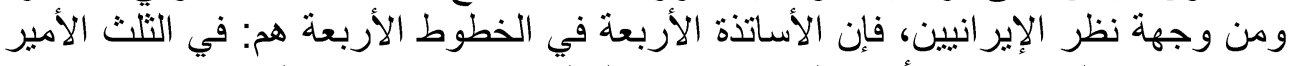

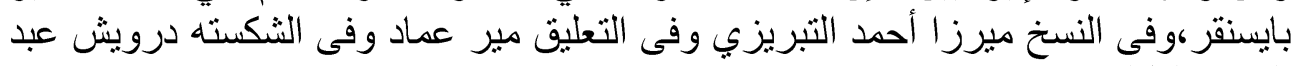

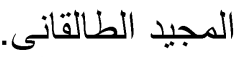

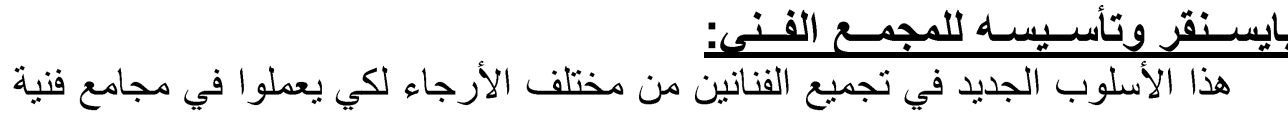

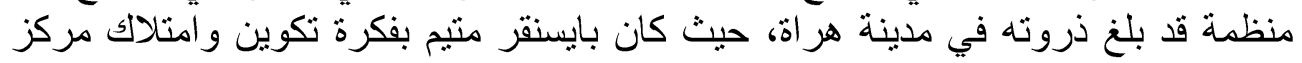

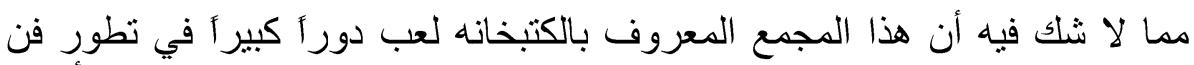

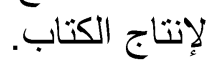

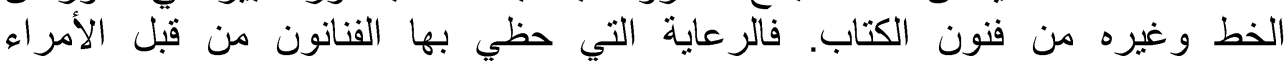

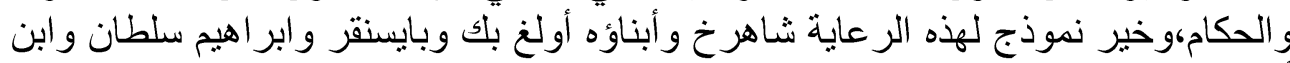

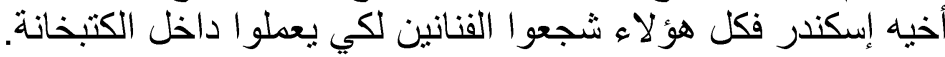

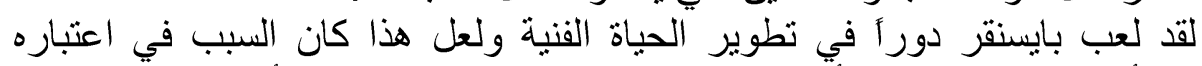

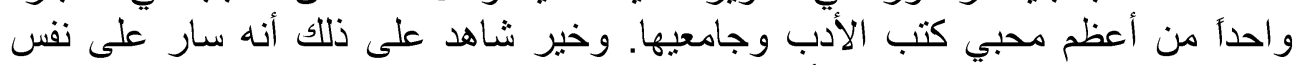

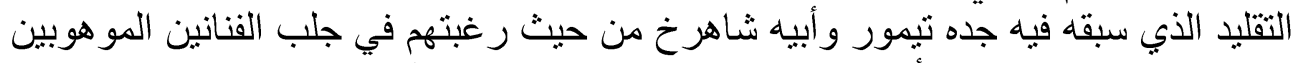

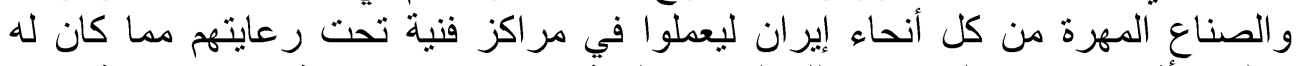

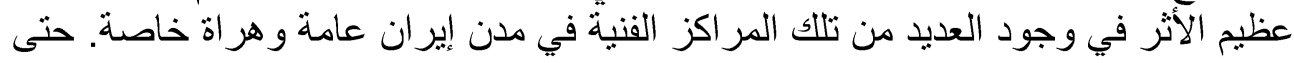


عُد بايسنقر مؤسسألأروع مدرسة لتزبين وتذهيب الكتب، وقد فاق عدد ما أنتج في زمانه

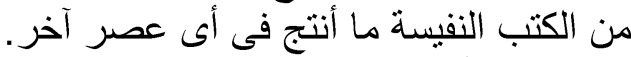

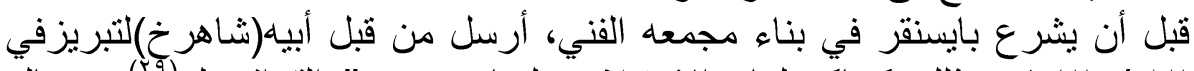

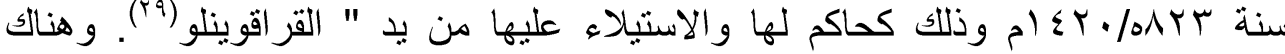

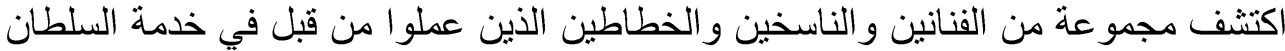

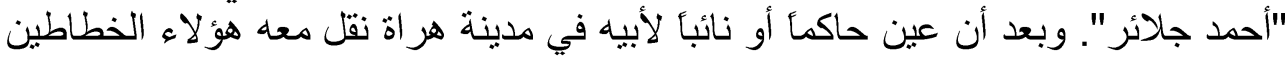

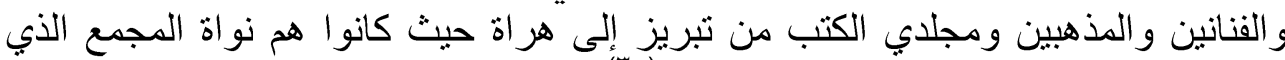

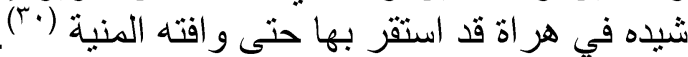
و عندئذ بدأ التأسيس للمجمع الفني و الذي كان يضم مرسمأ، كما كان يضم على الأقل

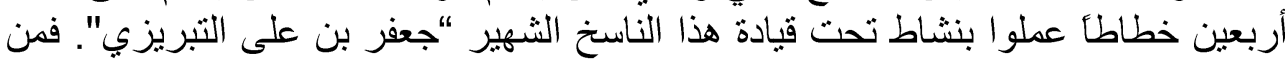

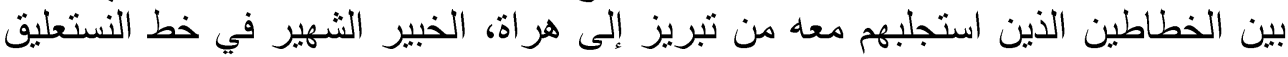

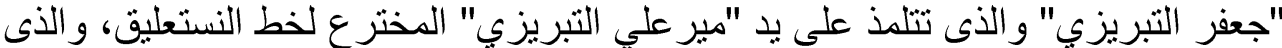

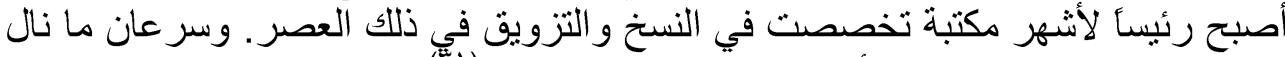

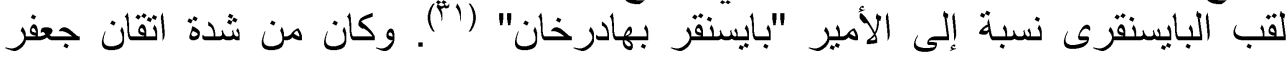

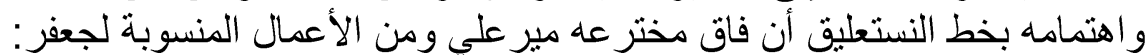

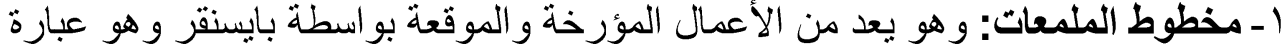

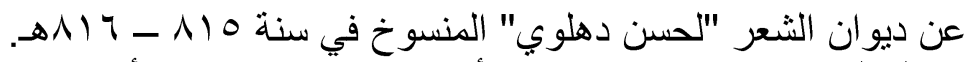

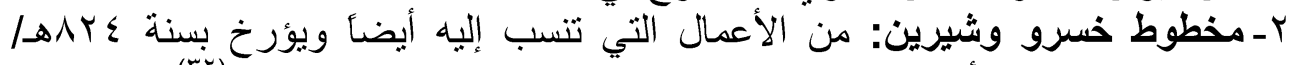

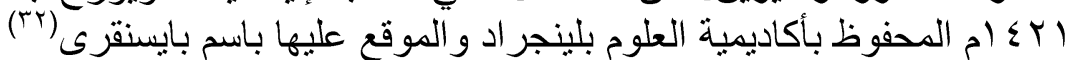

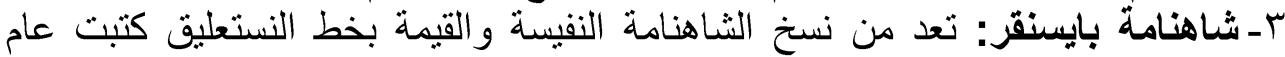

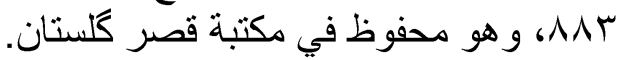
ومثلما جلب بايسنقر الفنانين من تبريز وفيتان وغير ها من البلاد، نجد أنه بعد وفاة "إسكندر

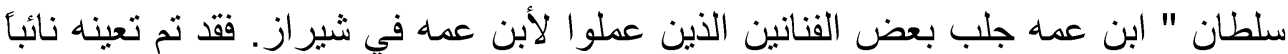
لأبيه، وكان من نتيجة ذلك أن أصبحت مجموعة فناني مكتبة اسكندر تحت تصني تصرف

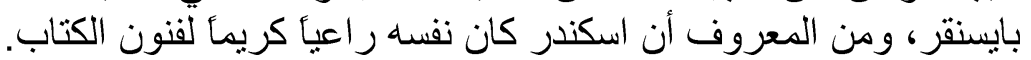

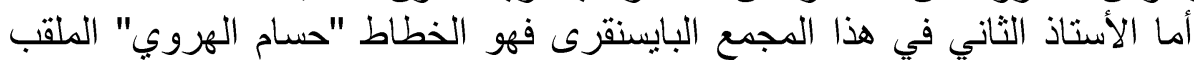

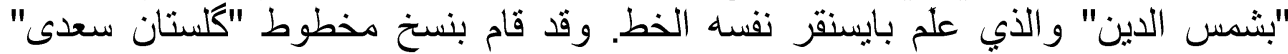

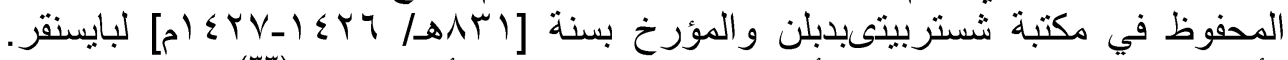

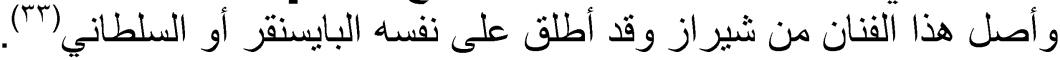

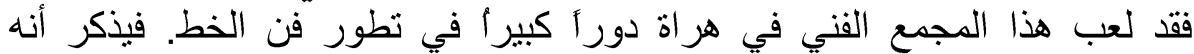
استخدم خمسين فنانأ لنسخ المخطوطات-كمانجد أن بيسنقر نفسه تحمل على فئ عاتقه اهتمام

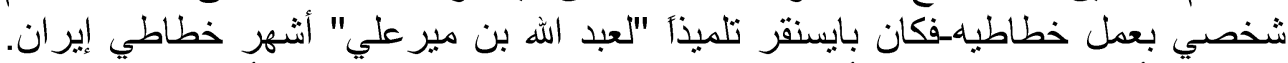

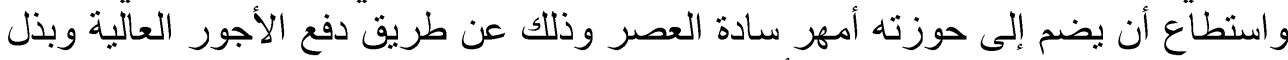

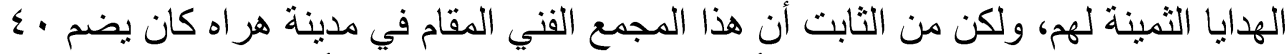

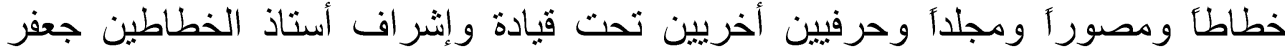

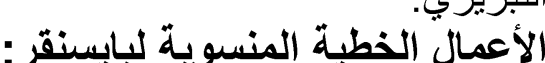
الأعمال التبريز

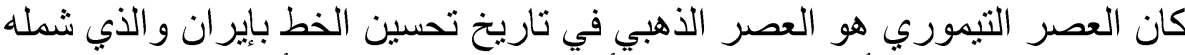

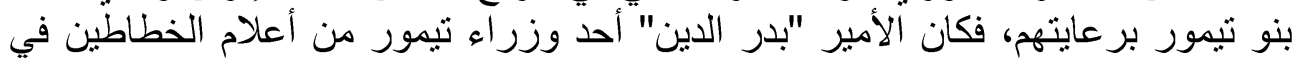


عصره. وقد ظهر في العصر التيموري نوعان آخران من الخط وهما الخط الديواني(r) والخط الدشتي.

أما إذا انتقلنا لبايسنقر فنجد أنه قد بقى عدد من النماذج الخطية المنسوبة إليه، منها

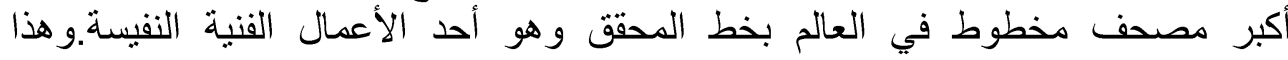

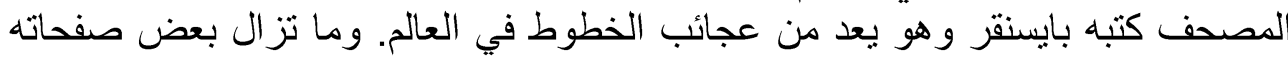

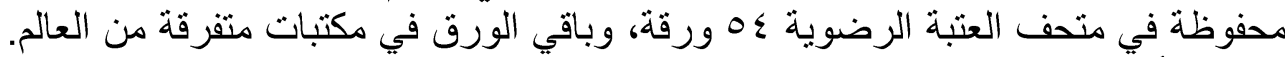

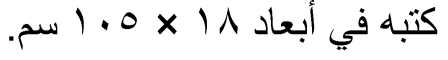

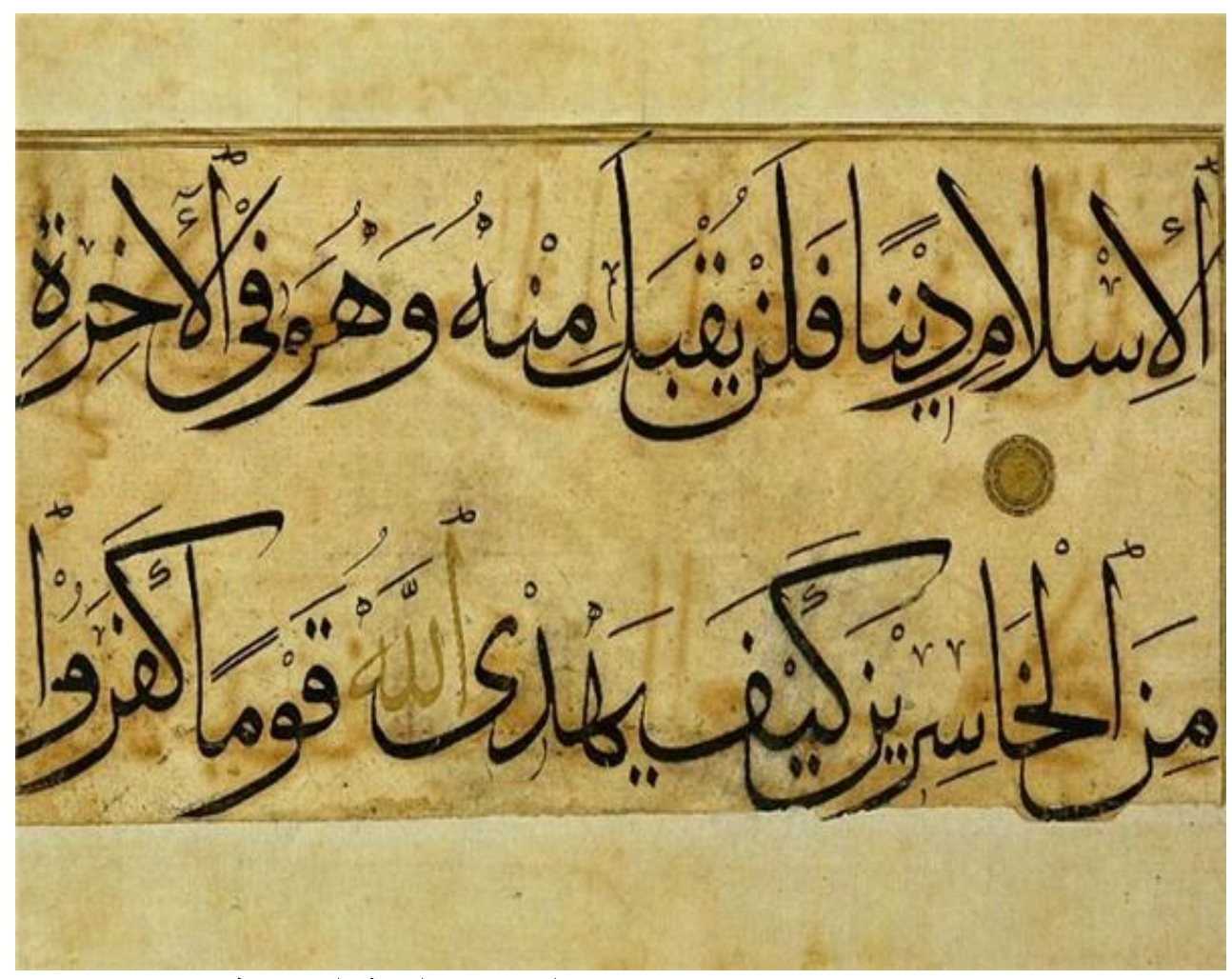

(صورة من مصحف بايسنقر الموجود بالعتبة الرضوية)

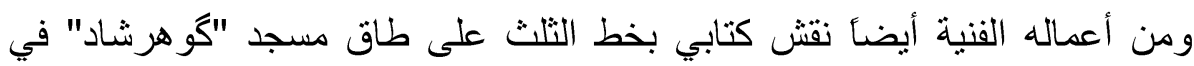
مشهد. و هذه اللوحة الفنية الرائعة التي انجز ها وهني وهو في العشرين من عمره تحكى اقتداره وقوة قلمه.

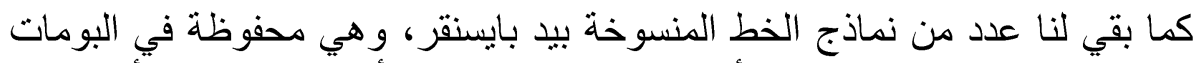

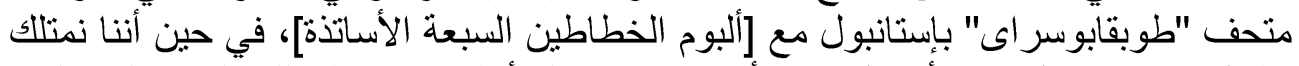

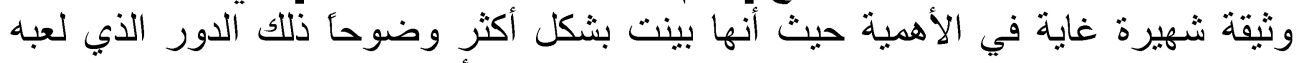

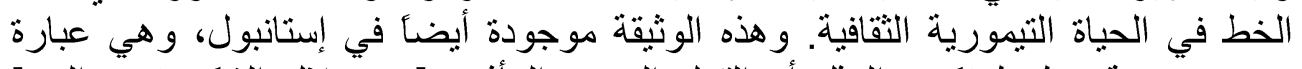

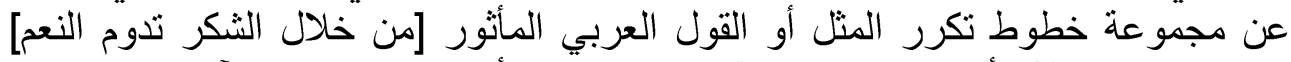

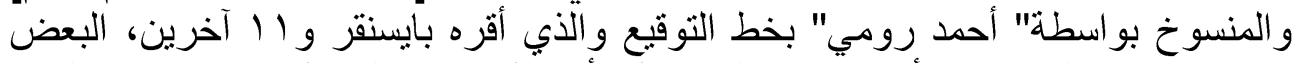

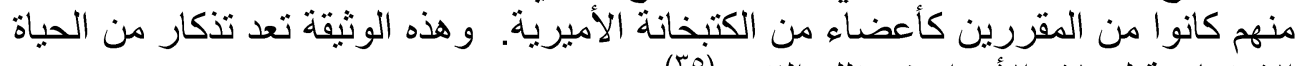

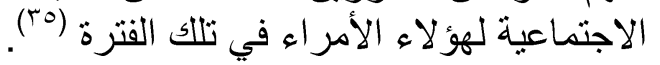




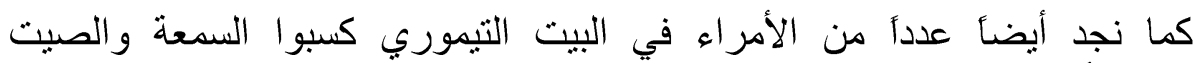

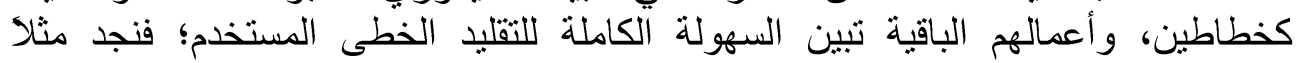

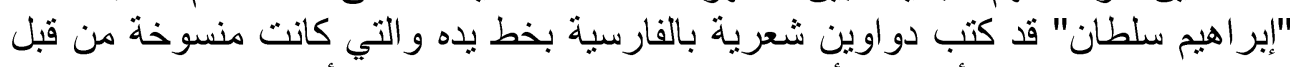

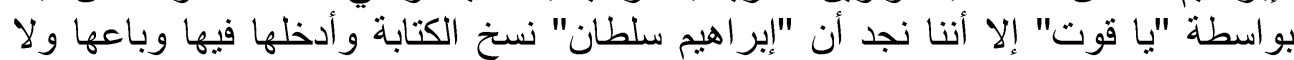

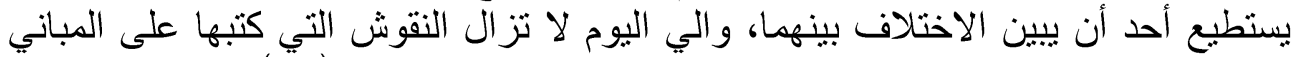

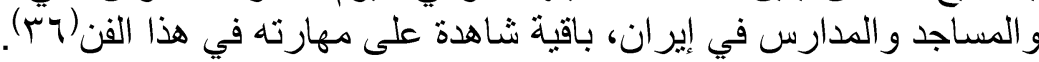

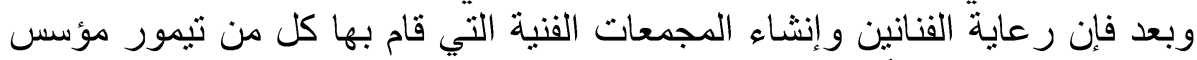

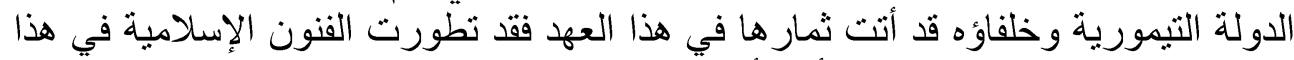
العهد بشكل ملفت للنظر. ومن أهم أفرع الفنون الإسلامية التي تطورت في هذا العهر

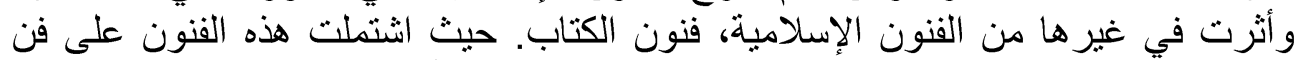

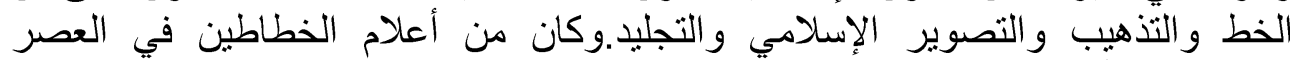

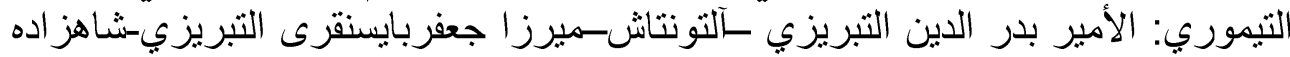

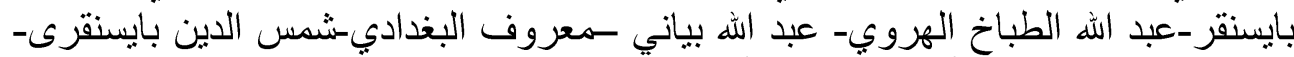

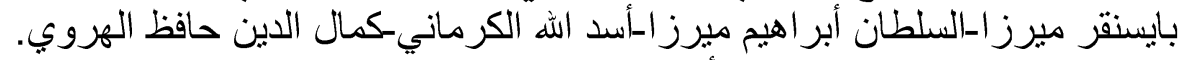

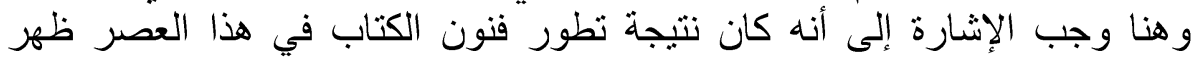

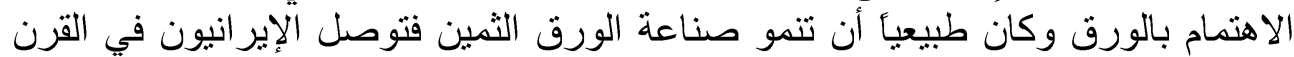

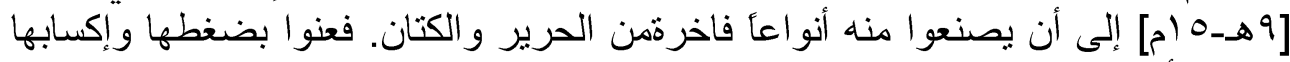

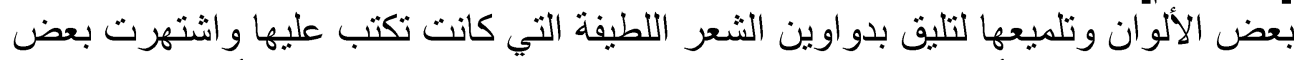

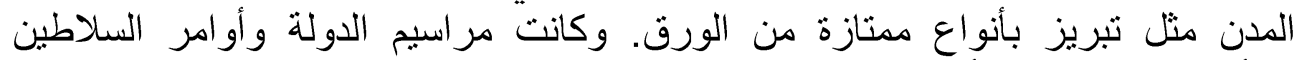

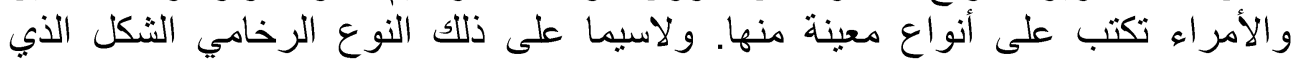

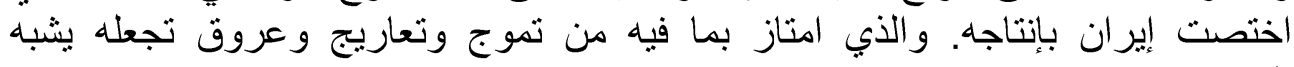

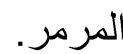

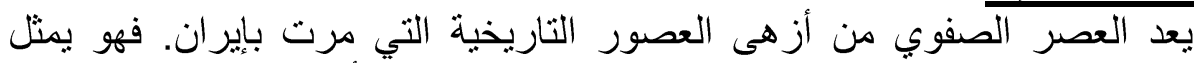

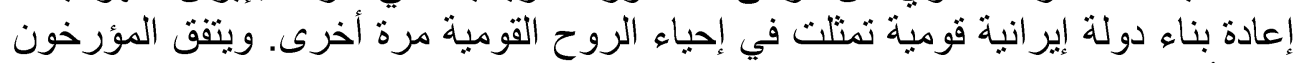

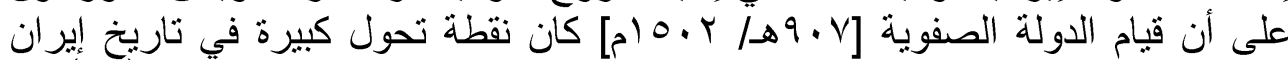

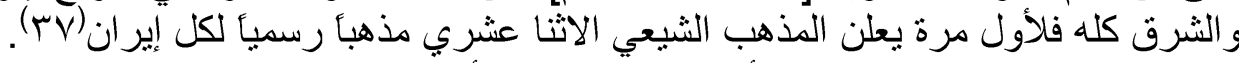

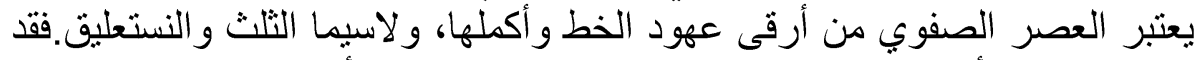

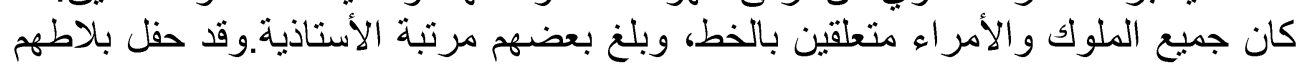

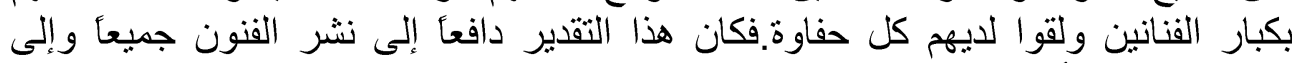

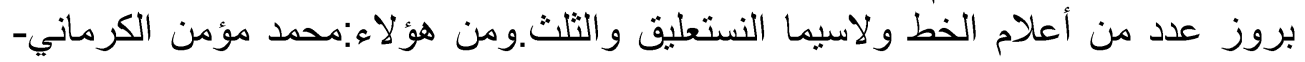

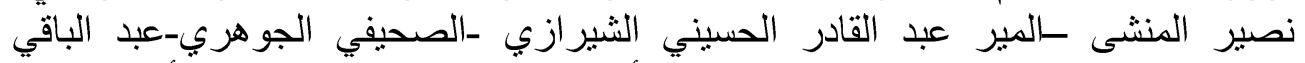

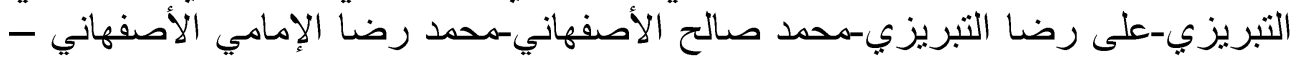
محمد حسن بن محمد رضئ رضا الإمامي.

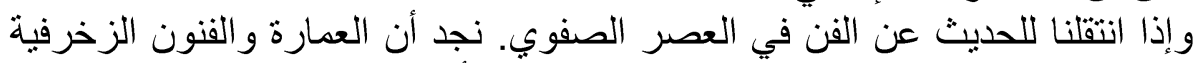

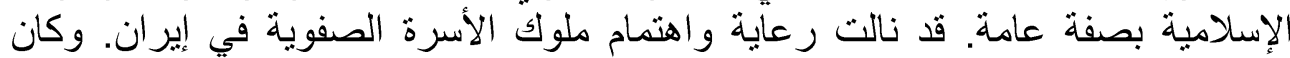

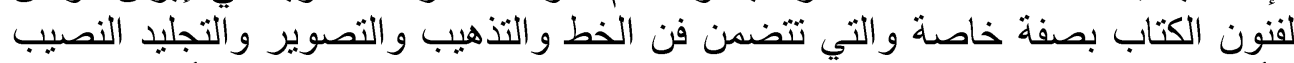

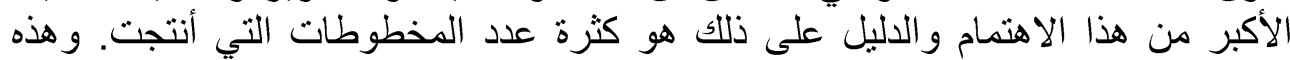

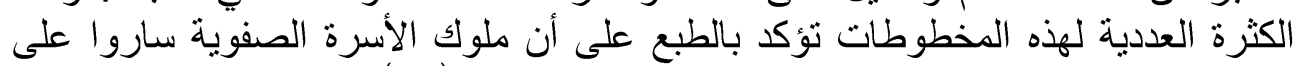

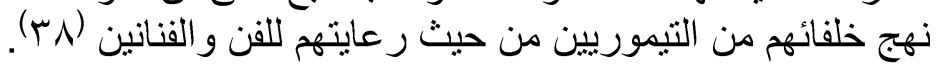


ولم يقق الأمر عند هذا بل إن أسلوب المدرسة التيمورية انتقل إلى المدرسة

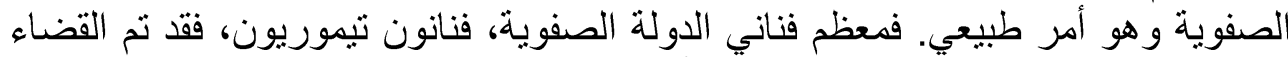

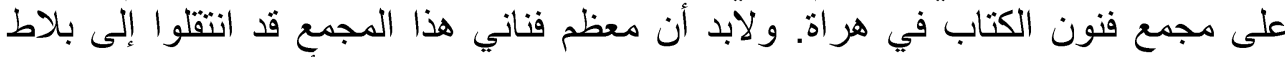

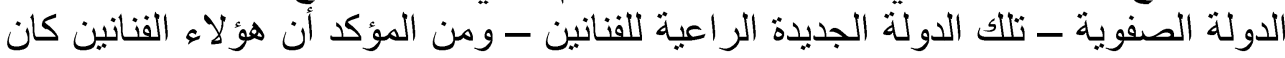

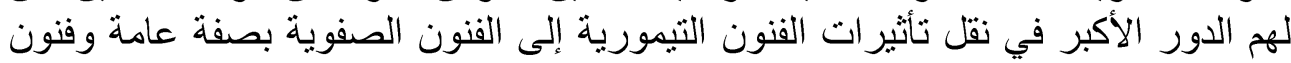
الكتاب بصفة خاصة.

فقد وصلت فنون الكتاب إلى أوج نموها في بداية العصر الصفوي. وكان وراء هذا

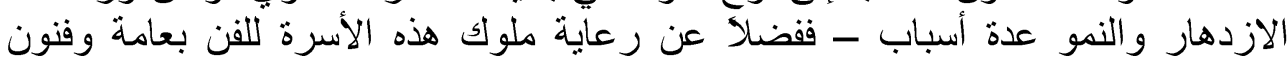

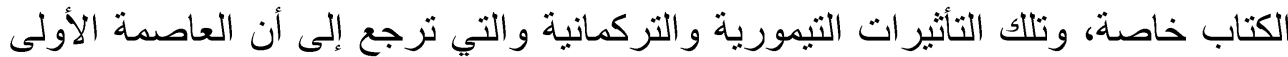
للملوك الصفويين وهي تبريز، كانت فيما سبق حاضرة التركمان، وكان طبيعياً أن تنتقل التركل التأثير ات التركمانية إلى الصفوبين تيرين.

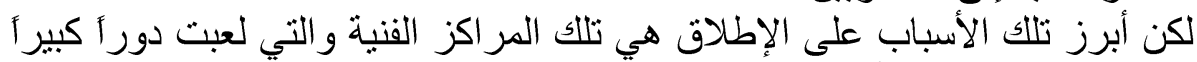
في العصر التيموري. فقد نشأ بداخلها مجمعات فنية تحوي فرق التهن عمل جماعية من خطاطين

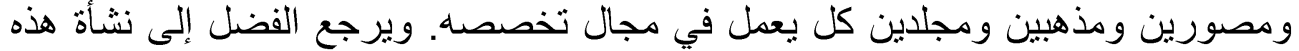

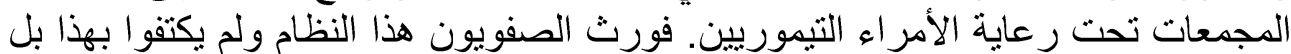

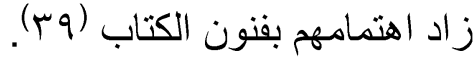
وكان من جر اء ذلك الاهتمام أن زاد عدد المر اكز الفنية في إيران في هذا العصر فقد الهاء كانت زيادة عدد المر اكز من الأشياء التي حرص أنيام عليها الصفويون منذ بداية عهدهم. فعندما

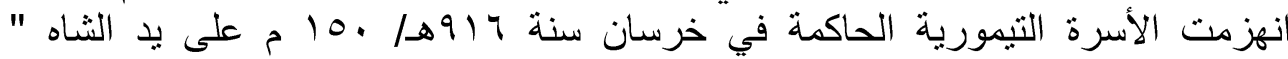

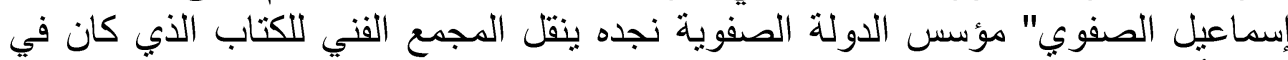

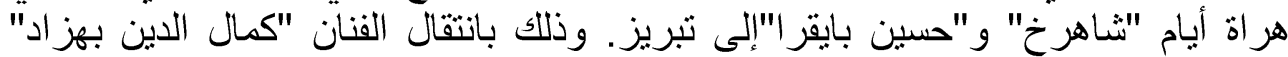
ومعه نخبة من الفنانين إليها حيث أسس مدرسته الفنية لتدريب النشه من هن هواة الفن.

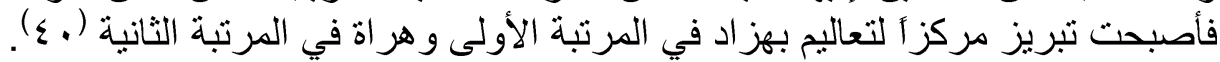

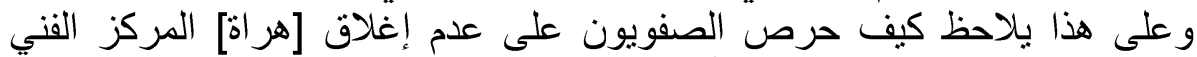

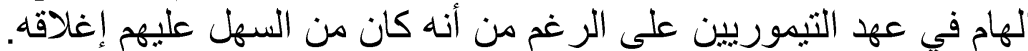

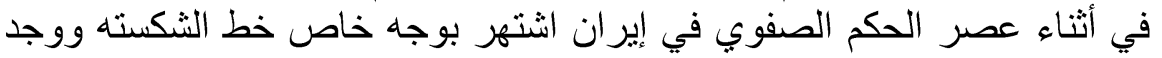

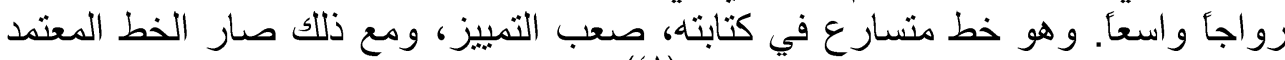

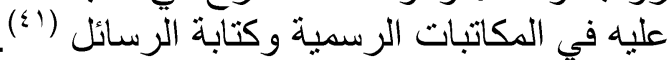

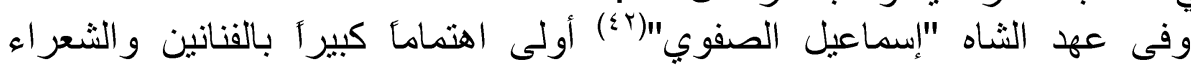

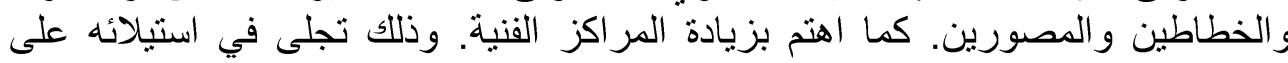

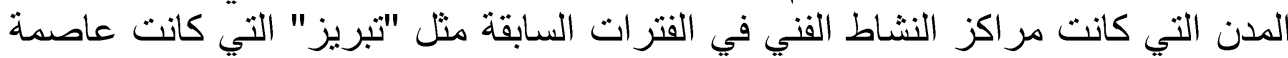

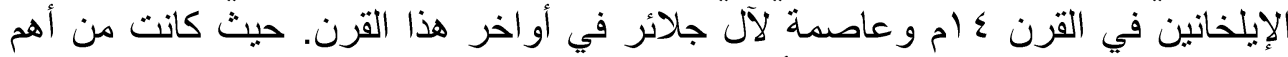

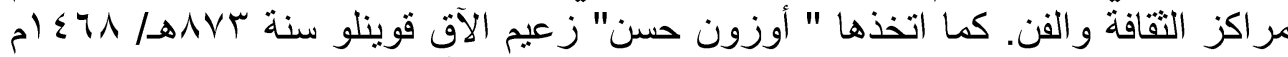

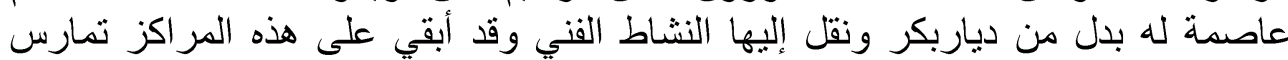

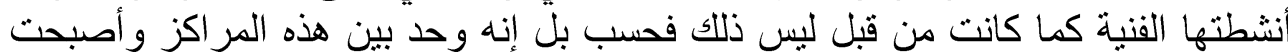
جميعها تعمل على نمط فني واحد. فاختقت كثير من الاختلافات الفنية الإقليمية التي كانت التهات

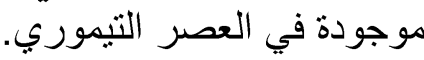
وقد كانت المكتبة الملكية في عهد هذا الثاه و التي عين "بهز اد" مدير ألها في عام

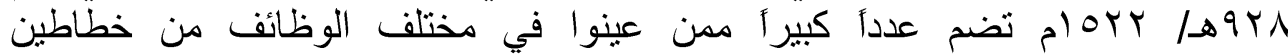
ومصورين ومذهبين ورسامي هو امش (مجدولين) ومتخصصين في سباكة الذهب وخلطة

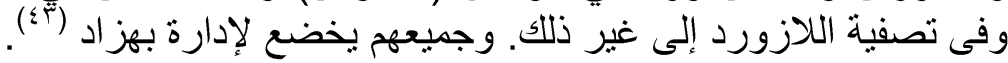




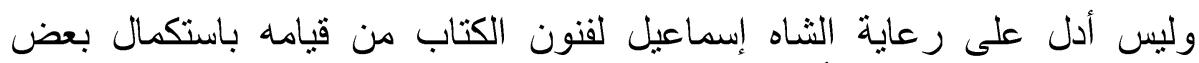

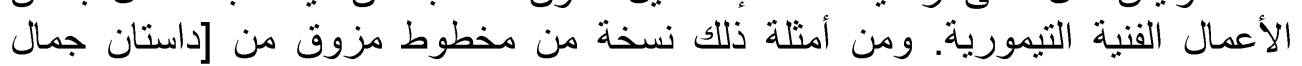

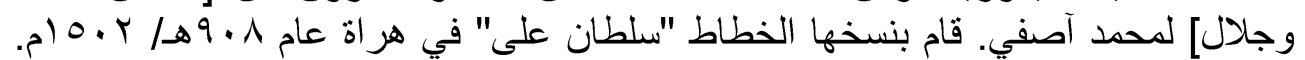

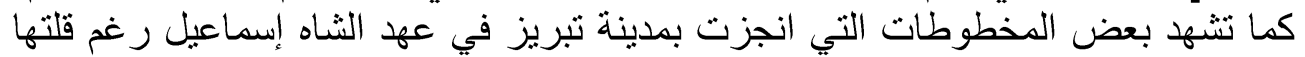

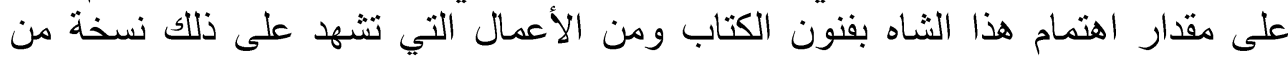

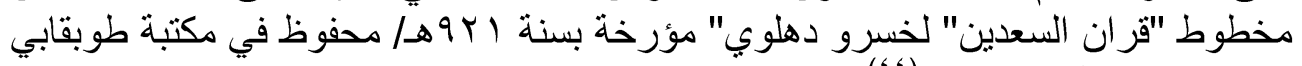

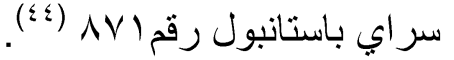

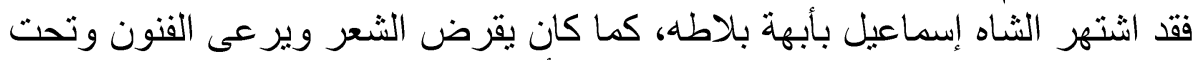

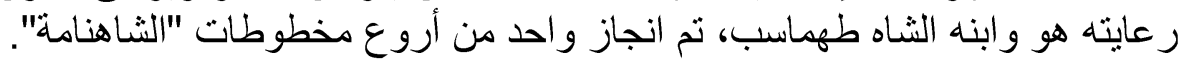

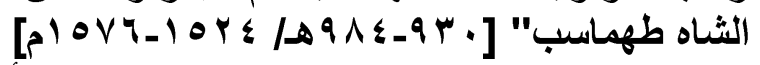

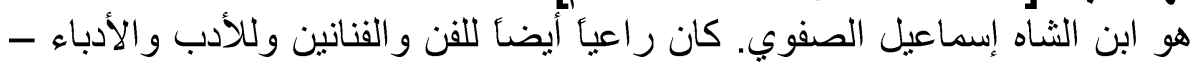

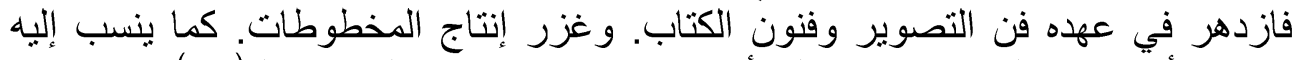

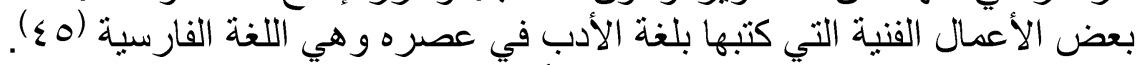

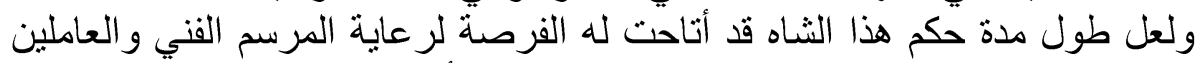

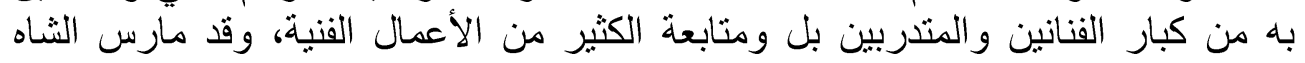

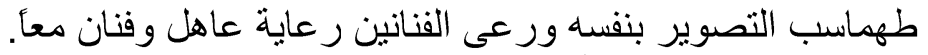

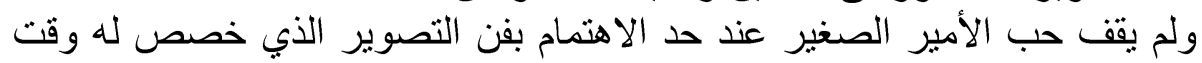

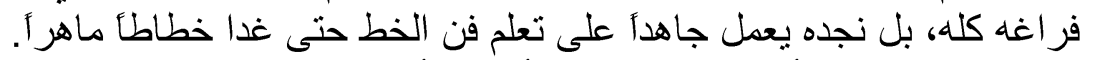

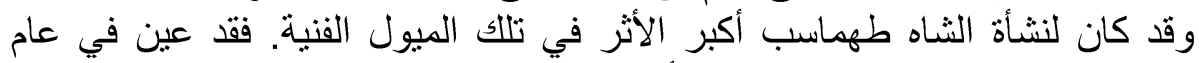

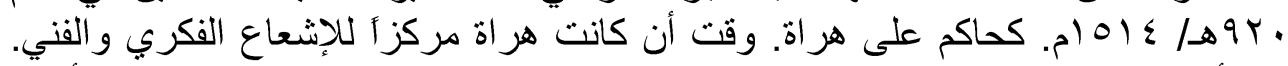

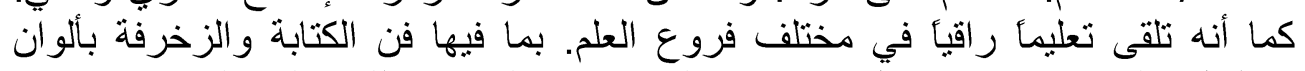

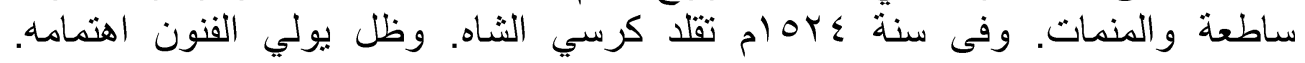

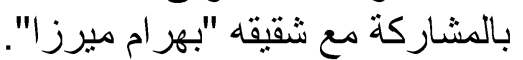

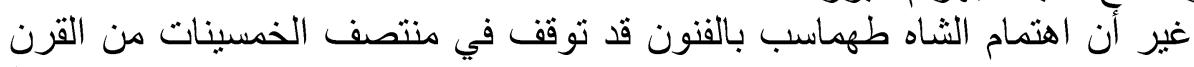

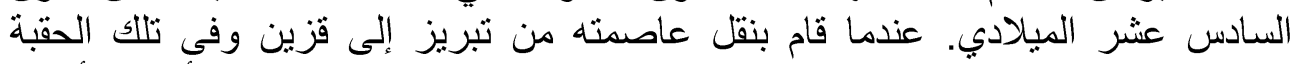

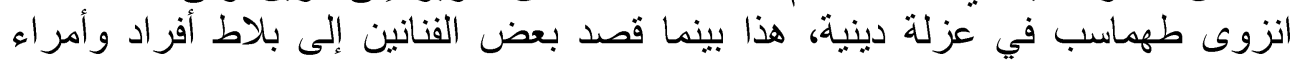

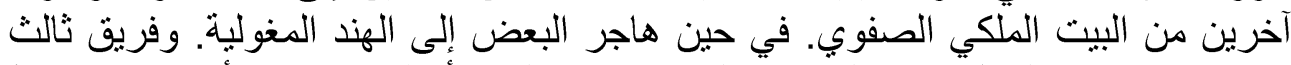

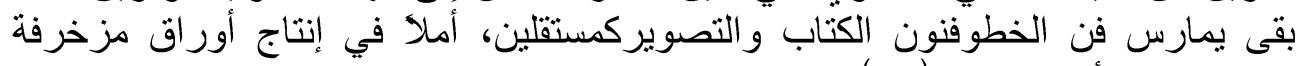

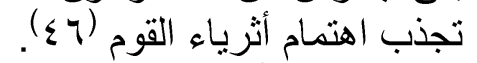

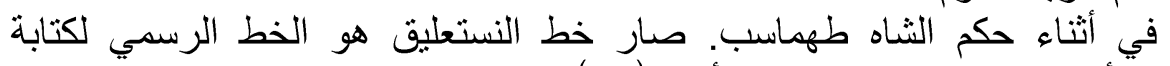
المقتطفات الأدبية، و الملاحم و الكتابات الأدبية (لحــ.

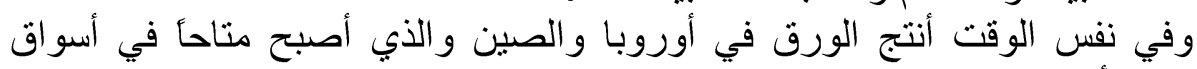

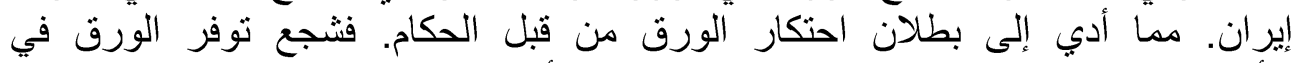

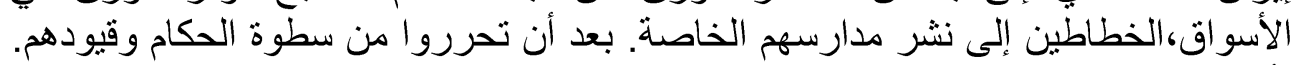

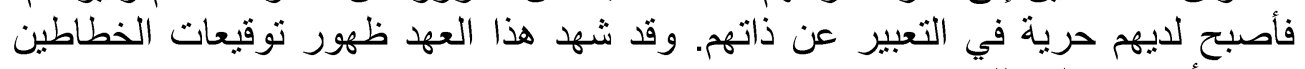
كجزء أساسي على لابهم حربة اللوحات.

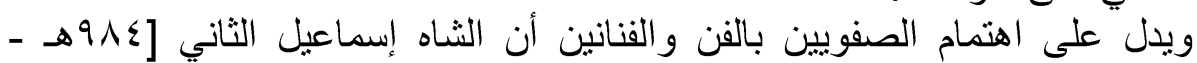

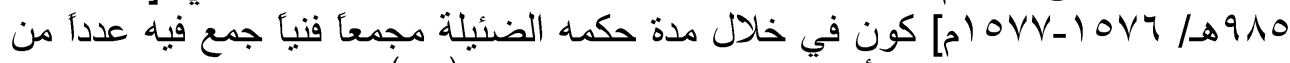

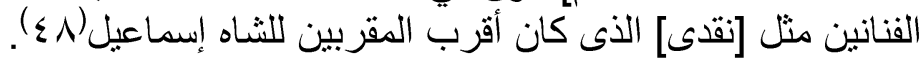


كذلك نالت العمارة والفنون رعاية واهتمام في عصر [الثاه عباس]. فبالنسبة للعمارة

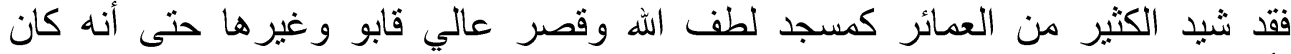

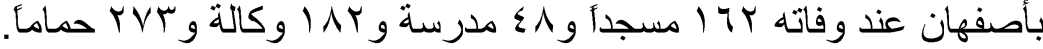

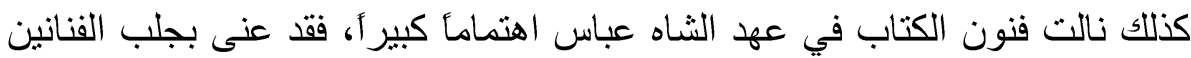

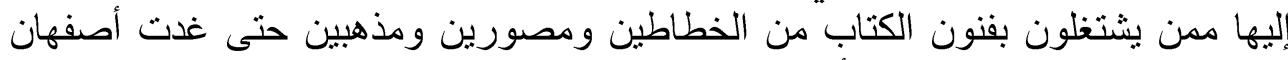

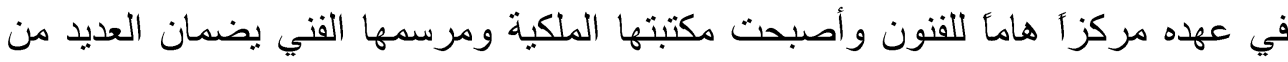

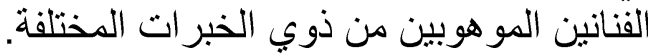

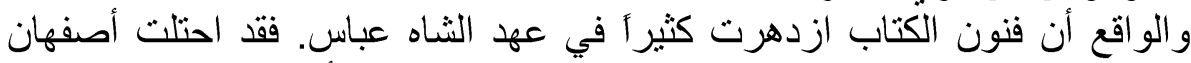

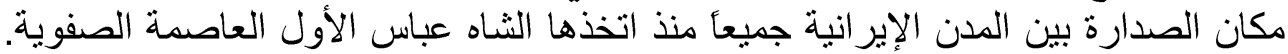

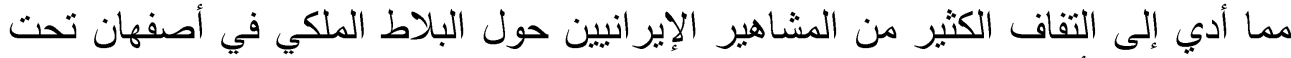

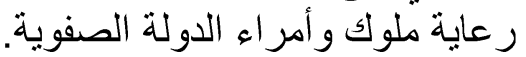

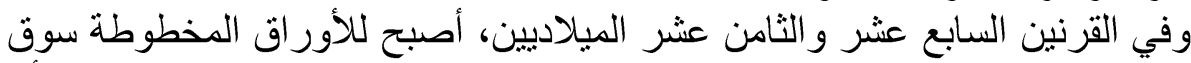

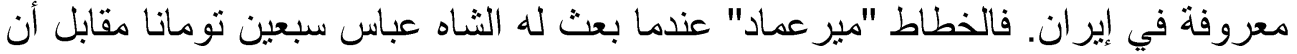

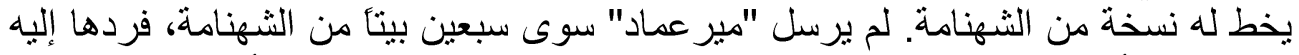

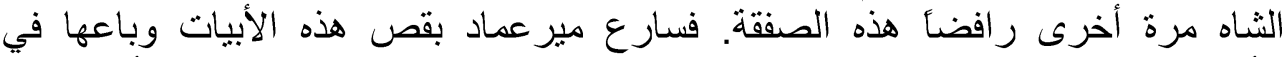

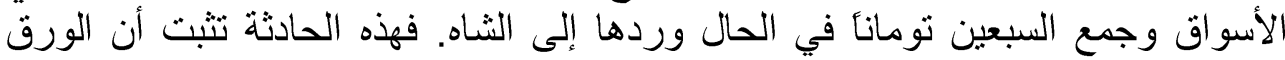

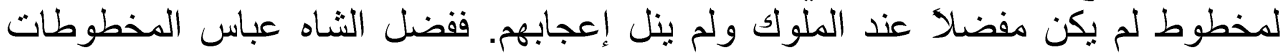
الكاملة و اهتم بالكم و الحجم بدلا من الاستماع بالخط الجمال الميل.

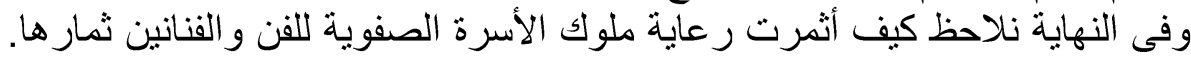

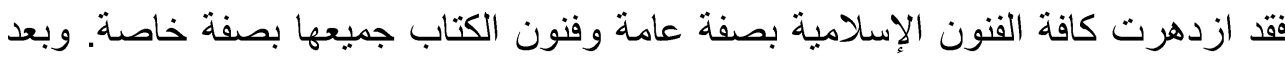

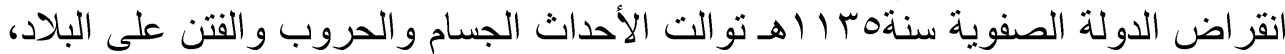

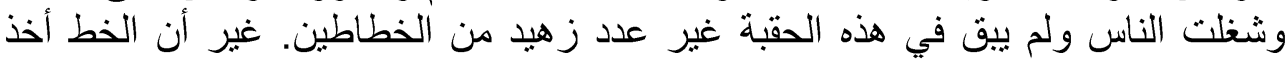

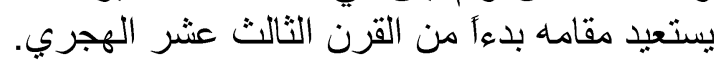




\section{Abstract \\ Care of kings and their impact on the development of the line By Iman Mokhtar Said}

This research deals with the great role played by the kings and princes of the dynasty of Timurid and Safavid in the development of "the art of calligraphy."

Calligraphy has played a very important role in the artistic life; and it have its own sanctity as it related to writing the Quran.

Researcher divided this research into an introduction and two parts, the first part deals with the Timurid era, and the second part deals with the Safavid era.

The researcher presented in each part the flourishing of the artistic life and the evolution of the art of calligraphy with the most important calligraphers in these periods and presented its most important business.

Researcher has been followed the historical approach, and relied on the Persian and Arabic sources and references.

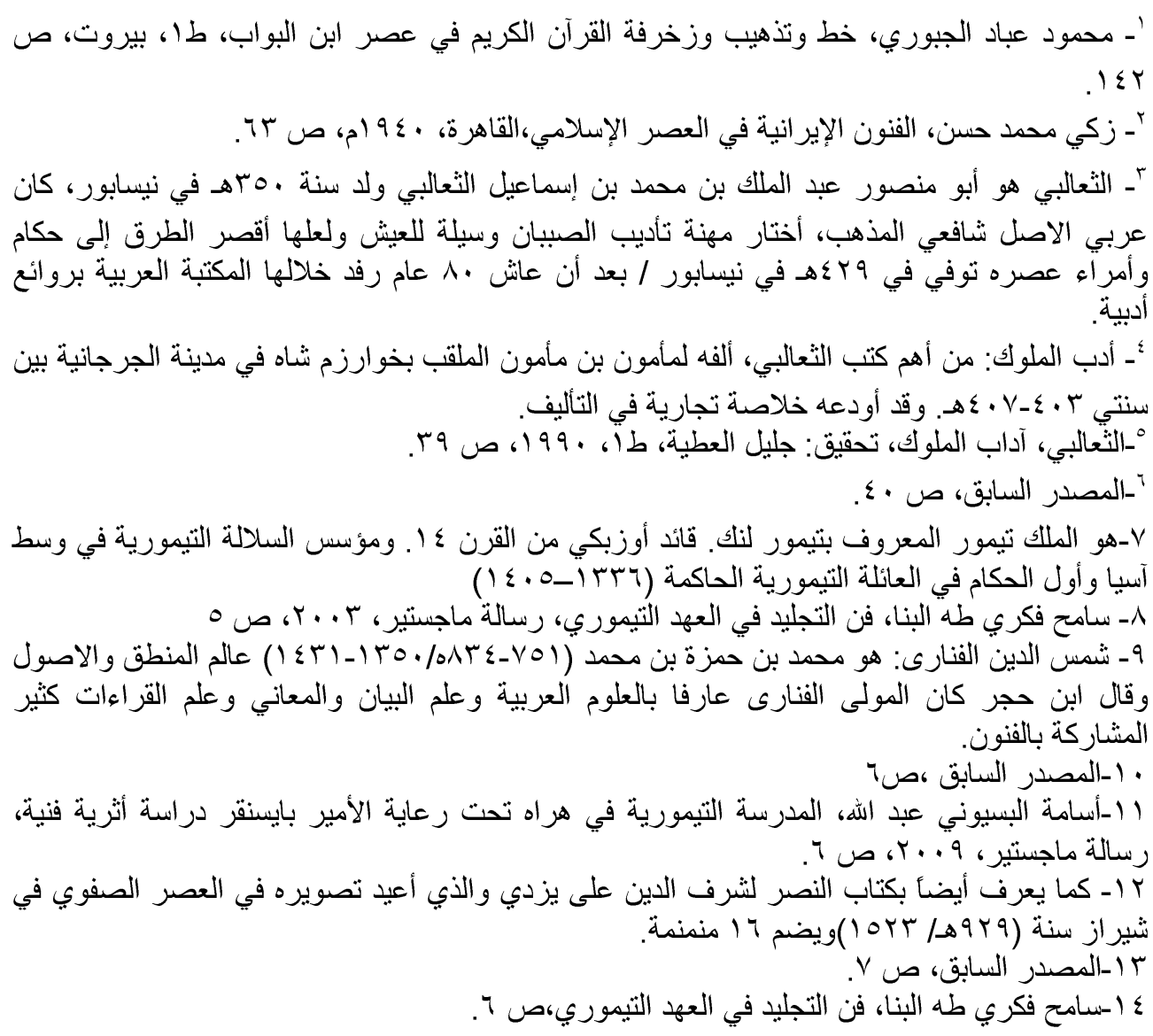


أ'أسامة البسبوني عبد الله، المدرسة التيمورية في هراه تحت رعاية الأمبر بايسقر دراسة أثرية فنية، ص

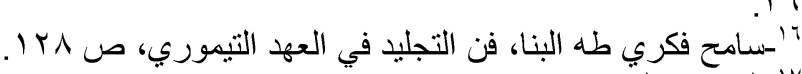

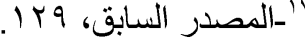

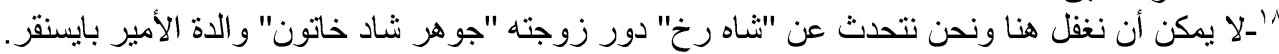

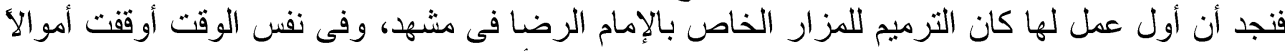

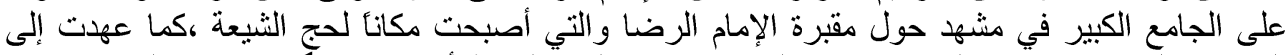

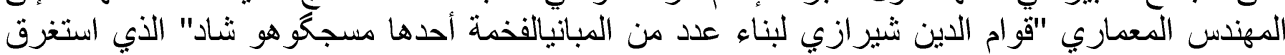

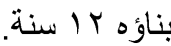
'.'أسامة البسيوني عبد اله، المدرسة التيمورية في هر اه تحت رعاية الأمير بايسقر دراسة أثرية فنية، ص

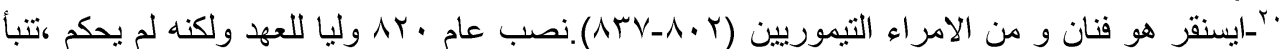

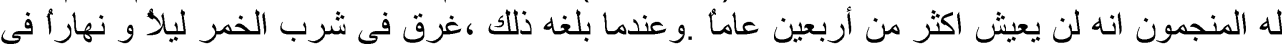

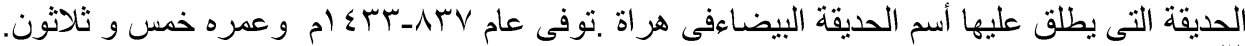

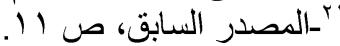

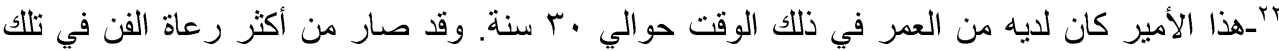

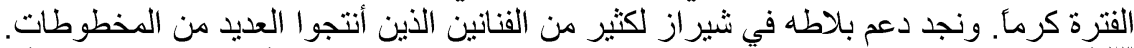

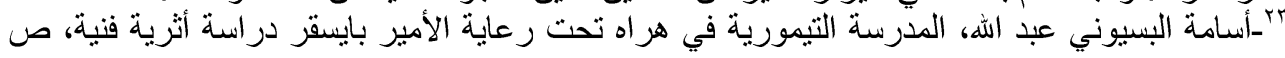

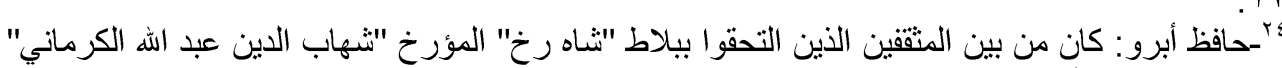

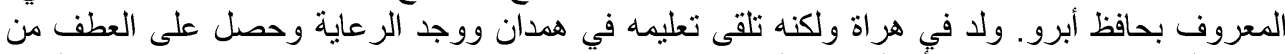

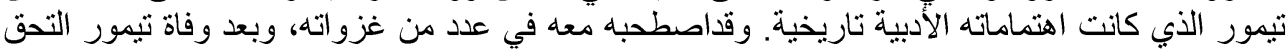

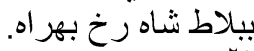

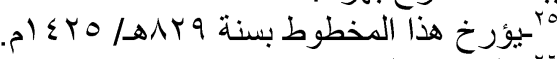

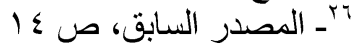

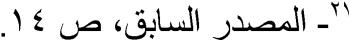

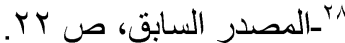

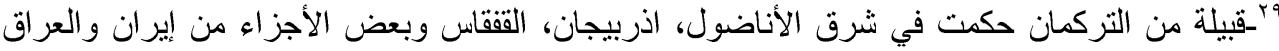

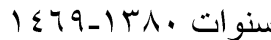

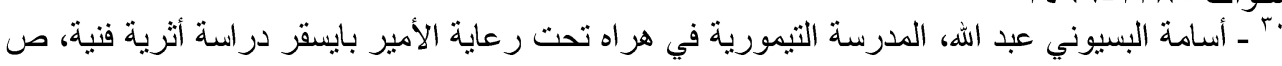

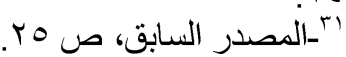

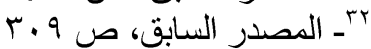

$$
\begin{aligned}
& \text { rrr }
\end{aligned}
$$

ع ז-الخط الديواني أو السلطاني هو أحد الخطوط العربية، سمى بالديواني والسلطاني نسبة إلى ديوان السلطان العثماني. حيث كان هذاً الخط يستعل في كئ كتابة المراسلات السلطانية.

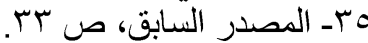

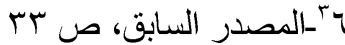

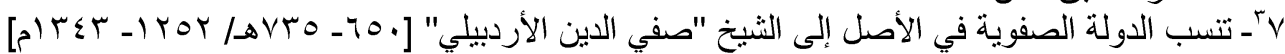

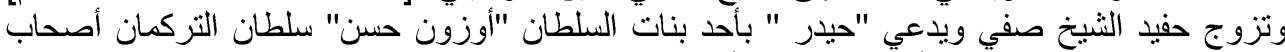

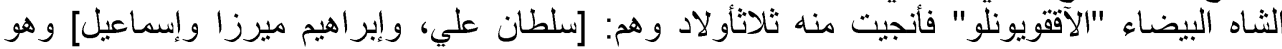
مؤسس الدولة الصفوية بإيران. ^^^ـسامح فكري البنا، فن التجليد في العصر الصفوي ـ رسالة دكتوراه ـ كلية الآثار، جامعة القاهرة ـ 


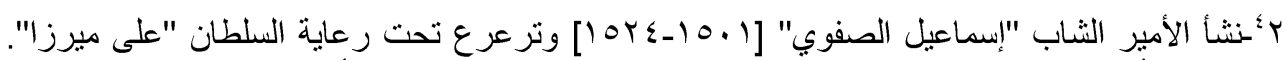

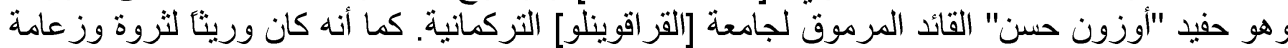

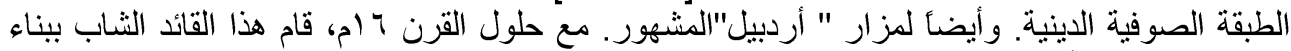

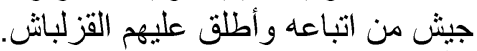

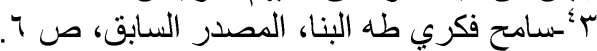

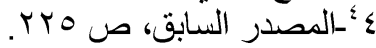

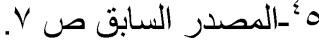

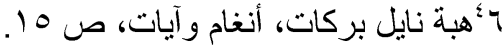

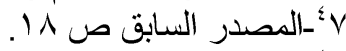

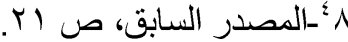

